\title{
Physiopathologie des maladies du système nerveux
}

\section{Briganti Giovanni et Pedini Michael}

Contact : giovanni.briganti@hotmail.com ; mikapedini@gmail.com 


\section{Neuropathies}

\section{Généralités et sémiologie}

Les nerfs périphériques sont composés de fibres nerveuses sensitives, motrices et autonomes. Ils se divisent en nerfs larges myélinisés, nerfs petits myélinisés et nerfs petits non myélinisés. Les neuropathies seront donc les atteintes des nerfs eux-mêmes, divisés en axonopathies (atteinte de l'axone), et myélopathie, tandis que la neuronopathie est l'atteinte du ganglion et la radiculopathie l'atteinte de la racine nerveuse. Au niveau sensitif, les plus grosses fibres véhiculent le sens de position, les plus petites la douleur et la température. Au niveau moteur, les fibres les plus grosses innervent des grandes unités motrices de muscles rapides anaérobies à grande force de contraction et fatigables, tandis que les petites fibres innervent des petites unités motrices de muscles lents aérobies à petite force de contraction et résistants à la fatigue. Le type de fibre, de contraction et de métabolisme du muscle dépend de son innervation.

Dans l'approche des neuropathies, il faut que le clinicien 1) identifie la lésion, 2) en détermine la cause et 3) en détermine le meilleur traitement. Souvent la cause reste non identifiée malgré un examen clinique neurologique étendu.

L'anamnèse des neuropathies comprend différentes questions, dont :

1. Quels systèmes sont atteints ? Il faut déterminer si il s'agit d'une neuropathie autonome, motrice, sensitive ou un mélange de celles-ci. Via l'anamnèse, on recherche des antécédents de chute orthostatique de la pression artérielle via ses symptômes (tête qui tourne, impression de tomber, etc.). La majorité des neuropathies sont sensitives.

2. Quelle est la distribution de la faiblesse ? Il faut déterminer le pattern de faiblesse : extrémité proximale, distale ou les deux? Est-ce que la faiblesse et focale et asymétrique, ou symétrique ? Par exemple, la faiblesse proximale, distale et symétrique dû à une neuropathie démyélinisante est déterminante du syndrome de Guillain Barré. Une faiblesse asymétrique multifocale sans signes sensoriels pourrait évoquer un diagnostic de sclérose latérale amyotrophique. 
3. Quelle est la nature de l'atteinte sensitive ? Perte de sensation, sensation altérée au toucher (allodynie ou hyperpathie). La douleur neuropathique peut être localisé de manière très peu définie (protopathique) et en type brulure. Si seulement la douleur et la température sont atteintes alors que tout le reste est normal, la neuropathie à petites fibres est probable.

4. Est-ce qu'il y a une preuve d'atteinte du motoneurone supérieur? La cause principale d'une neuropathie avec symptômes sensoriels distaux symétriques et neuropathie distale est la déficience en Vitamine B12, mais aussi d'autres pathologies dégénératives comme le SIDA et des infections pourraient être considérées.

5. Quelle est l'évolution temporelle ? Aigue ( $<4$ semaines), subaigüe (4 à 8 semaines), chronique (>8 semaines). Le parcours peut être monophasique, progressif ou intermittent. Les neuropathies avec une présentation aigue ou subaigüe comprennent le syndrome de Guillain Barré, la vasculite et des radiculopathies dues au diabète ou la maladie de Lyme. Un parcours intermittent pourrait évoquer une atteinte chronique et inflammatoire démyélinisante.

6. Y-a-t-il une preuve d'atteinte héréditaire? Surtout chez les patients atteints d'une faiblesse lentement progressive distale étendue sur plusieurs années avec peu de présentations sensorielles on pourrait considérer une neuropathie héréditaire (Charcot Marie Tooth). Il faudrait donc tester via des études électrophysiologies et examens neurologiques le reste de la famille proche.

7. Y-a-t-il d'autres pathologies affectant le patient ? Diabète, maladies auto-immunes, chirurgies digestives (neuropathies nutritionnelles). 


\section{Etudes électrophysiologiques (et électromyographiques) dans l'évaluation des neuropathies}

Le reflexe $\mathrm{H}$ consiste en la stimulation des fibres sensitives du nerf tibial postérieur au niveau du creux poplité. On enregistre la réponse motrice au niveau du muscle soléaire. La stimulation de la fibre sensitive IA, qui remonte dans la moelle par la corne postérieure et se transmet via synapse avec un motoneurone alpha présent dans la corne antérieure doit générer une réponse reflexe qui est étudiée. L'absence de réponse bilatéralement peut signaler une polyneuropathie, ou peut être physiologique chez la personne âgée. Si absente unilatéralement peut être un signe d'une radiculopathie S1.

La vitesse de conduction est la vitesse à laquelle une impulsion électrique se propage dans un nerf. Elle est mesurée au niveau moteur, sensitif et mixte. Les paramètres étudiés sont la vitesse de conduction bien évidemment, qui peut nous donner des renseignements sur le diamètre des fibres et l'état de la myéline, et l'amplitude ainsi que la morphologie de la réponse, qui nous renseigne sur le nombre d'axones et l'état musculaire. La vitesse de conduction normale dans le membre supérieur est entre 50 et $70 \mathrm{~m} / \mathrm{s}$ et de 40 et $60 \mathrm{~m} / \mathrm{s}$ dans le membre inférieur.

Pour mesurer la vitesse de conduction deux électrodes sont posées à deux points distants d'un nerf (par exemple le médian). La vitesse de conduction motrice sera mesurée en stimulant en amont et en mesurant la réponse en aval en tenant compte du temps de fusion synaptique dans la région de l'unité motrice. L'inverse sera effectué pour la mesure de la vitesse de conduction sensitive, celle ci ne tenant pas compte bien évidemment du temps de fusion synaptique.

\section{Caractéristiques électrophysiologiques de l'atteinte axonale et démyélinisante}

L'atteinte axonale est caractérisée par une diminution des amplitudes et une légère diminution des vitesses de conduction. L'atteinte démyélinisante est caractérisée par une forte diminution des vitesses de conduction (30 à 40\%) et une préservation des amplitudes de réponse.

L'augmentation de la latence distale est l'augmentation du temps de réponse périphérique de la réponse musculaire, elle est observée dans les atteintes démyélinisantes. La dispersion temporelle, également présente dans les atteintes démyélinisantes est la dispersion des réponses musculaires 
enregistrées suites à la lésion du nerf qui crée des vitesses différentes. Le bloc de conduction, absence de réponse suite à une stimulation à un endroit défini du muscle, est présent lors d'une atteinte démyélinisante.

La réponse $\mathrm{F}$ (ou onde $\mathrm{F}$ ) est la réponse tardive observée suite à la stimulation d'un axone: en stimulant au milieu d'un axone, la réponse primaire est celle allant de la zone de stimulation jusqu'en périphérie (réponse F), tandis que la réponse $\mathrm{F}$ est la réponse tardive passant par le soma du neurone est redescendant l'axone. Cette onde est absente lors de l'atteinte démyélinisante d'un nerf.

En résumé: l'atteinte axonale est caractérisée par une diminution des amplitudes, l'atteinte démyélinisante est caractérisée par une diminution de la vitesse de conduction, un bloc de conduction, une augmentation du temps de latence distale, une absence de l'onde $\mathrm{F}$ et une dispersion temporelle.

\section{Electromyographie et potentiels d'unité motrice dans l'évaluation de l'atteinte axonale}

L'électromyographie (EMG) est la méthode la plus acceptée pour définir l'atteinte axonale, via la mesure des axones moteurs et des activités anormales. Les fibrillations, positive sharp waves, sont des activités anormales perçues lors de l'EMG lors d'une dénervation. Parmi les causes d'activités spontanées anormales figure l'hypersensibilité des récepteurs à l'acétylcholine : suite à la dénervation, l'hypersensibilité produit des contractions spontanées de fibres musculaires en réponses à des faibles quantités d'acétylcholine qui en temps normaux ne produit pas de contraction.

Le potentiel d'unité motrice (PUM), de durée moyenne de $15 \mathrm{~ms}$, est mesuré lors de l'EMG. Lors d'une lésion neurogène, un neurone préexistant et intact prendra en charge via des fibres néoformées l'unité motrice restant sans innervation: le résultat à l'EMG est un PUM large, de longue durée et désynchronisé symbolisant la réinnervation. Le PUM sera augmenté en amplitude lorsque l'unité motrice impliquée est plus grande.

En résumé : la dénervation cause des fibrillations, la réinnervation cause des PUM plus larges et les unités motrices plus grandes causent des PUM augmentés. 


\section{Charcot Marie Tooth de type 1}

La neuropathie de Charcot Marie Tooth (CMT) de type 1 est une neuropathie démyélinisante sensorimotrice (HMSN, neuropathie sensorimotrice héréditaire), caractérisée par une vitesse de conduction inférieure à $38 \mathrm{~m} / \mathrm{s}$. A caractère autosomique dominant, les gènes le plus souvent mutés se trouvent sur le chromosome 17 (17p11.2) codant pour la protéine PMP 22 (CMT1A), ou sur le chromosome 1q21-23 (CMT1B) codant pour la protéine MPZ, responsable de la compaction de la myéline et interagissant physiquement avec PMP22. La surexpression de l'une par rapport à l'autre due à la mutation du gène cause un défaut de compaction de la myéline responsable de la maladie.

La CMT1 débute le plus souvent durant la première décade de vie $(75 \%)$, et elle est rarement asymptomatique pendant la 3ème décade. Les symptômes initiaux sont des troubles de la marche, déformation du pied. Les signes plus fréquents sont l'aréflexie des membres inférieures chez la totalité des patients, la marche sur talon perturbée, l'atrophie des muscles du pied, l'hypertrophie des nerfs, le pes cavus et des tendons d'Achille raccourcis.

La production augmentée de myéline cause, dans les nerfs ou la perte d'axone est moins sévère, des bulbes d'oignons : la gaine de myéline est initialement plus épaisse que la normale, et tardivement les axones deviennent fins, et lorsque la maladie progresse, de moins en moins d'entre eux seront myélinisés.

\section{Charcot Marie Tooth de type 2, 3, 4 et CMTX}

CMT2 est une neuropathie axonale sensitive dont la vitesse de conduction est supérieure à $38 \mathrm{~m} / \mathrm{s}$ par définition. CMT3 est principalement démyélinisante, tandis que CMT4 peut être soit axonale soit démyélinisante.

CMTX est une neuropathie liée à l'X (gène GJB1) avec une diminution de la Connexine 32, homologue de la PMP22 dans la myéline non compacte. Chez l'homme CMTX se présente comme une neuropathie démyélinisante tandis qu'elle a une forme axonale chez la femme. 


\section{Hereditary Neuropathy with liability to pressure palsies (HNPP ou neuropathie tomaculaire)}

HNPP est une maladie autosomique dominante apparaissant principalement entre 10 et 30 ans $(70 \%)$.

Liée à la CMT1A, qui est causée une copie extra de 1,5 Mb du gène codant pour la PMP22, la HNPP est causée par l'hérédité d'un chromosome manquant ce même gène (délétion). La forme principale est déclenchée suite à un trauma mineur relié à une augmentation de pression (mettre un sac à dos, s'étirer) qui comprime les nerfs atteints (fibulaire et ulnaire) causant un engourdissement et une faiblesse indolore qui prend parfois des mois à se résoudre (récupération complète $50 \%$ ). Chez certains individus la forme est chronique et plus sévère ressemblant au CMT1.

Les signes sont: pied creux, aréflexie achilléenne et dans certains cas généralisés, amyotrophie, et scoliose. L'électrophysiologie montre une augmentation des latences distales avec une perte d'amplitude et des blocs de conduction. Les tomacules (saucisses) sont des signes retrouvés lors de la biopsie du nerf révélant des zones épaissies due à la dégénérescence axonale.

Il n'existe pas de traitement pour cette pathologie, éviter les compressions pour prévenir l'aggravation des symptômes.

\section{Neuropathies sensitives et autonomiques héréditaires (HSAN)}

HSAN 1 est une maladie autosomique dominante débutante entre 10 et 30 ans et caractérisée par des douleurs lancinantes ainsi qu'une diminution de la sensibilité à la température et la douleur aux membres supérieurs et inférieurs à début distal. Des ulcérations du pied non douloureuses peuvent être présentes, ainsi qu'une diminution des réflexes et de la transpiration. Une discrète atrophie et faiblesse distale sont observées.

HSAN 2 est une maladie autosomique récessive débutante à l'enfance est caractérisée par une diminution de la sensibilité à la douleur et à la température aux 4 membres, distale et proximale. Les ulcérations et les fractures sont fréquentes, ainsi que des atteintes des lèvres et langue, une aréflexie distale et une neuropathie axonale.

HSAN 3 est caractérisée par des ulcérations de la peau et de la cornée ainsi que des déformations articulaires fréquentes, une aréflexie généralisée et une neuropathie axonale. Les symptômes 
autonomes seront plus marqués (hypertension, hypotension orthostatique, diminution lacrymatoire, température fluctuante).

HSAN 4 et 5 sont autosomiques récessives, accompagnés d'une insensibilité congénitale à la douleur avec anhydrose et un retard mental. Ce sont des neuropathies axonales avec mutation du gène NTRK1 récepteur tyrosine kinase 1 à neurotrophine.

\section{Maladie de Fabry}

La maladie de Fabry est une maladie héréditaire dominante liée à l'X. Elle se présente par des angiokératomes diffus (lésions maculopapulaires) avec des complications plus graves (comme l'athérosclérose, causant des complications entrainant le décès du patient dans la 5ème décade, ou des cardiomyopathies dilatées). Des douleurs lancinantes des mains et des pieds sont parfois présentes dès la fin de l'enfance. La maladie est causée par une altération de l'alpha-galactosidase qui cause une accumulation de céramide dans les vaisseaux et nerfs. Une thérapie de substitution enzymatique peut être entamée si la maladie est découverte précocement. Pour le traitement des douleurs neuropathique isolées, une prise de carbamazépine est conseillée.

\section{Canal Carpien}

Compression du nerf médian au niveau du poignet sous le ligament antérieur du carpe. Troubles sensitifs et moteurs dans le territoire d'innervation du nerf médian. Troubles moteurs : problème de flexion des phalanges des $2^{\text {ème }}$ et $3^{\text {ème }}$ doigts et du pouce (main du prédicateur). Troubles sensitifs : paresthésie (fourmillements) apparaissant la nuit (réveil nocturne), au volant ou à la lecture. Paresthésie souvent diminuée en secouant la main. Signes : atrophie thénarienne (court adducteur du pouce), faiblesse de la main et paresthésies.

\section{Polyneuropathie Amyloïde Familiale}

L'Amyloïdose familiale est une maladie autosomique dominante avec une mutation de la transthyrétine (TTR) synthétisée dans le foie et les plexus choroïdes. Cette protéine mutante forme des dépôts de fibrilles d'amyloïde dans le tissus graisseux, nerveux ou dans le rectum. Les dépôts favorisent l'accumulation de TTR, causant un cercle vicieux. Les symptômes se présentent dans l'âge 
moyen, avec un début de neuropathie périphérique et autonome, une cardiomyopathie et des opacités vitrées. Le traitement consiste essentiellement à une transplantation hépatique dès l'apparition des premiers symptômes de la maladie (10\% étant asymptomatiques on attend le début des symptômes).

\section{Amyloïdose acquise}

Elle est causée par des dépôts d'amyloïde causant une polyneuropathie périphérique et autonomique secondaire parmi d'autres signes (cardiomyopathie, hépatomégalie, protéinurie, macroglossie).

\section{Neuropathie diabétique}

La neuropathie secondaire au diabète peut se présenter sous différentes formes.

La neuropathie à prédominance sensitive s'étend au niveau des jambes, des mains et la partie antérieure du thorax en débutant au niveau des pieds (chaussettes), avec une aréflexie achilléenne.

Si les petites fibres sont atteintes il y aura présence d'une altération de la température et de la douleur avec apparition d'ulcères, tandis que si les grosses fibres sont altérées le sens de position sera altéré.

La neuropathie autonome peut se manifester avec des hypotensions, tachycardies, impuissance, anomalies de la miction, gastro parésie, diarrhées nocturnes.

Le mécanisme de toxicité du diabète sur les nerfs est complexe et comprend différentes voies dont une voie métabolique (hyperglycémie et stress oxydatif $\rightarrow$ pseudo hypoxie et dysfonctionnement du nerf), une voie vasculaire (formation de plaque d'athérome dans vaisseaux vascularisant des nerfs) et une voie immunitaire (vasculites, provoquant une diminution du flux de sang destiné aux nerfs).

Les fibres atteintes sont surtout celles de petit calibre.

La neuropathie diabétique est liée au degré d'hyperglycémie. Un traitement intensif permet de diminuer les symptômes neurologiques. 


\section{Syndrome de Guillain Barré}

Le syndrome de Guillain Barré consiste en une atteinte immunitaire aigue à évolution monophasique précédée dans 2/3 des cas par des antécédents d'infection (C. Jejuni, CMV, EBV, Mycoplasme ou HIV). Il s'agit d'une polyradiculonévrite aigue inflammatoire démyélinisante ou d'une neuropathie aigue motrice axonale. La gaine de myéline est détruite par les anticorps, les lymphocytes $\mathrm{T}$ attaquant les peptides de la myéline ou par le système du complément dans une forme typique. La forme axonale est caractérisée par une destruction de l'axone par des anticorps sur le nœud de Ranvier ou par des macrophages envahissant le nœud. Les symptômes sont différents selon l'atteinte : par exemple, lors de la forme axonale Miller Fisher G1Qb détruit le nerf oculomoteur ou le nerf optique.

Le traitement se fait par immunothérapie (plasmaphérèse/injection d’Ig intraveineuses) et accélère la récupération du syndrome en diminuant le temps de séjour en soins intensifs. Le risque principal de mort est dû à l'arrêt respiratoire.

\section{Gammapathies}

En temps normal, les lymphocytes B produisent des anticorps en cas d'infections. Avec l'âge, certains lymphocytes dysfonctionnent et produisent de manière incontrôlée un type d'anticorps. Ce dérèglement reste le plus souvent bénin (on reste dans des quantités raisonnables) : 200 bénignes pour 1 maligne. $19 \%$ des gens de plus de 95 ans présentent une gammapathie. Dans 60\% des cas, c'est une gammapathie à IgG. Ces gammapathies monoclonales ont tendance à développer des neuropathies surtout s'il s'agit d'une gammapathie à IgM. Les neuropathies engendrées par les gammapathies à IgM sont surtout démyélinisantes. Plus de 50\% des neuropathies associées à une gammapathie à IgM présentent des ATC anti-MAG (Myeline Associated Glycoprotein). Il y a des dépôts d'IgM qui se forment sur la myéline, ce qui empêche une bonne compaction de la gaine de myéline entraînant de facto une neuropathie démyélinisante.

5 types de traitements: plasmaphérèse (comme SBG) mais pas très efficace, injection d'immunoglobulines en intraveineuse (comme SBG) mais pas très efficace, analogues nucléosides, agents alkylants (médicaments toxiques contre la lignée «mutante» de lymphocytes B, Rituximab, 
ATC monoclonal produit artificiellement ciblant antigène CD20 à la surface des lymphocytes B entraînant sa destruction (traitement le plus efficace).

Remarque : le Rituximab est surtout utilisé dans les pathologies hématologiques cancéreuses (stock en faveur des cancéreux). 


\section{Maladies de la Jonction Neuromusculaire}

\section{Généralités et rappels neurophysiologiques de la jonction neuromusculaire}

La jonction neuromusculaire définit l'ensemble formé par l'extrémité neuronale synaptique, la fente synaptique et la plaque motrice. Dans le neurone, l'arrivée du potentiel d'action ouvre des canaux calcium P ou Q voltage dépendant qui font entrer le calcium permettant la fusion de 150 à 200 vésicules $(1$ vésicule $=1$ quantum ou 1 quantum $=1000$ molécules; plusieurs vésicules =quanta $)$ d'acétylcholine (ACh) à la membrane et le relargage de cette molécule dans la fente synaptique. Une fois dans la fente, les molécules d'ACh se fixent sur les récepteurs à $\mathrm{ACh}(\mathrm{AChR})$, récepteurs formés de 5 sous unités ( 2 alpha, 1 beta, 1 delta, 1 gamma ou epsilon) qui permettent l'entrée d'ions sodium générant une dépolarisation locale, le End Plate Potentiel (EPP), qui, atteint un seuil déclenchant, génère le potentiel d'action musculaire. L'ACh est ensuite dégradée par l'acétylcholine estérase (AChE). Lors des stimulations répétées, la déplétion du compartiment primaire se traduit par une diminution du nombre de quanta et donc de l'amplitude des EPP, pouvant être objectivés par une étude électrophysiologique. Après quelques secondes de stimulation, le réapprovisionnement du compartiment secondaire en ACh permet une augmentation des amplitudes EPP. Ces diminutions d'amplitudes des EPP restent chez le sujet sain au-dessus d'un seuil de sécurité.

Les canaux P ou Q sont la cible du LEMS (Lambert Eaton Myasthenic Syndrome), tandis que les AChR sont la cible de la myasthénie (Myasthenia Gravis ou MG).

\section{Physiopathologie, définition, clinique sémiologique et électrophysiologique de la myasthénie}

Les anomalies neuromusculaires de la myasthénie sont déclenchées par une réponse auto-immune via des anticorps anti-AChR. Ces anticorps agissent via différents mécanismes pour réduire in fine le nombre total d'AChR: 1) accélération du turnover des récepteurs $A C h R$ via des mécanismes d'endocytose, 2) dégâts de la membrane post-synaptique musculaire via anticorps en collaboration avec le complément, 3) blocage du site actif de l'AChR. Un thymus hyperplasique (ou tumoral chez $10 \%$ des patients) semble être à l'origine de la réponse immunitaire exagéré et auto-entretenue. Les anticorps peuvent aussi cibler une kinase musculaire (MuSK) qui s'occupe de regrouper les AChR. 
La myasthénie est un syndrome moteur pur, se manifestant via des atteintes des muscles proximaux et extra oculaires (atteinte bulbaire). La cause peut être immunologique (comme énoncé ci-dessus), ou congénitale, avec variation de canaux lents ou rapides et déficits sévères en $\mathrm{AChR}$ ou $\mathrm{AChE}$. Elle peut être aussi déclenchés par des troubles métaboliques ou toxiques comme l'hypermagnésémie ou le botulisme. Le froid diminue le décrément par diminution de l'activité de cholinestérase sur ACh.

L'atteinte oculaire se manifeste par une ptose et une atteinte des muscles extra oculaires et des nerfs oculomoteurs, principalement au cours de la maladie $(90 \%, 50 \%$ au début) générant une diplopie. L'atteinte bulbaire se manifeste par une difficulté à la mastication, la parole (dysarthrie), à la déglutition (dysphagie) et de la fatigabilité.

Le diagnostic de la myasthénie se fait via différentes méthodes: essentiellement, une mesure par radioimmunoassay (mais pas uniquement, puisque les résultats définitifs prennent longtemps à être déterminés), sensible chez $85 \%$ des patients avec myasthénie et chez $50 \%$ des patients avec atteinte limitée au niveau extra oculaire (une mesure négative n'exclut pas une myasthénie), et une stimulation répétée du nerf (qui est dépassée en clinique par le EMG à fibre unique) qui met en évidence une diminution de plus de $25 \%$ de la réponse à $3 \mathrm{~Hz}$. Des tests plus simples pour mettre en évidence la maladie sont fréquemment utilisés, comme le test du comptage (on conte jusqu'à l'apparition de la dysarthrie), et le test du glaçon (agissant sur l'AChE). Le jitter (délai entre stimulation nerveuse et contraction musculaire) est augmenté : il est mesuré via un EMG à fibre unique.

Le traitement de la myasthénie se fait par inhibiteur de cholinestérase (pyridostigmine), immunosuppression par corticostéroïdes ou azathioprine, échanges plasmatiques et IVIg. 


\section{Myasthenic Syndrome (LEMS)}

Le syndrome myasthénique de Lambert Eaton (LEMS) est un désordre myasthénique présynaptique causé par des anticorps dirigé s contre les canaux calcium $\mathrm{P} / \mathrm{Q}$ voltage dépendants. L'entrée limitée de calcium entraine une diminution du relargage d'ACh dans la fente synaptique se traduisant par une moindre réponse musculaire. Le LEMS n'est pas purement moteur, à différence de la myasthénie, atteignant également le système nerveux sensitif et autonome. Les symptômes moteurs les plus fréquents incluent une faiblesse proximale des muscles des membres inférieurs, mais d'autres muscles peuvent être affectés également. On peut observer des ptoses et des diplopies.

Les symptômes autonomes incluent une sécheresse de la bouche et de l'impuissance.

La stimulation nerveuse répétée (RNS) à $3 \mathrm{~Hz}$ (basse fréquence) produit initialement une diminution de l'amplitude de réponse, mais avec de l'exercice continu ou une stimulation répétée à $20 \mathrm{~Hz}$, après la diminution on observe une augmentation (RNS >100\%) ce qui n'est pas le cas chez le myasthénique, qui obtiendra pour une RNS haute fréquence une récupération égale à 100\%.

La stimulation nerveuse répétée à haute fréquence étant trop douloureuse pour le patient, après avoir pris la mesure de la réponse au repos, on lui demande d'effectuer un effort maximal volontaire de 10 secondes, et ensuite on stimule à nouveau mesurant la réponse qui sera augmentée de 7 à 8 fois. Le jitter est augmenté également comme dans la myasthénie lors de sa mesure via EMG à fibre unique.

La plupart des patients atteints de LEMS ont aussi un cancer associé (ce qui rend la manifestation LEMS une forme paranéoplasique) comme par exemple le Small Cell Lung Carcinoma, qui utilise des canaux calcium de même type qui pourraient stimuler une réponse immune. Le diagnostic de LEMS est utile pour détecter très précocement les cancers associés. La forme auto-immune se distingue par le manque d'atteinte respiratoire et bulbaire et la présence unique de faiblesse des membres inférieurs et quelques muscles associés.

Le traitement du LEMS inclut le 3,4 diaminopyridine (3,4 DAP), la plasmaphérèse, les IVIg, et l'immunosuppression par corticoïdes. 


\section{Physiopathologie, définitions, clinique sémiologique et électrophysiologique du botulisme}

Le botulisme du à l'ingestion une des 7 toxines potentielles produites par Clostridium Botulinum via de la nourriture contaminée est un désordre présynaptique de la jonction neuromusculaire interférant avec les enzymes de la fusion vésiculaire. Les toxines sont composées d'une chaine légère et d'une chaine lourde, cette dernière va rentrer dans le neurone en périphérie en interférant avec les protéines SNARES (Q-SNARE: syntaxine, SNAP-25, et R-SNARE: synaptobrévine et synaptotagmine): l'acétylcholine n'est donc plus libérée, causant une absence de contraction musculaire.

Les symptômes, dans leur ordre respectif d'apparition, sont: sécheresse de la bouche (24h après l'ingestion), diplopie, dysphonie, dysphagie, tetraparésie des membres supérieurs et inférieurs, et propagation aux muscles respiratoires pouvant induire l'arrêt respiratoire et la mort.

Au niveau des potentiels musculaires (CMAP) on peut observer une diminution d'amplitude, la présence d'une facilitation post-exercice dans la phase précoce, une dénervation chimique par présence de positive sharp waves et de fibrillations. Les PUMs sont normaux à aspect myopathique.

Le traitement antitoxine devrait être débuté le plus tôt possible, accompagné d'une assistance ventilatoire et un traitement de support agressif. Un vaccin est disponible pour les travailleurs de laboratoires et les personnes à risque. 


\section{Myopathies}

\section{Généralités}

Une myopathie est une atteinte structurelle ou fonctionnelle du muscle qui peut être génétique ou acquise. Les myopathies sont différenciées des neuropathies et des jonctions neuromusculaires, même si la présence de ces deux dernières peut cacher une myopathie sous-jacente.

\section{Physiopathologie des présentations cliniques}

Un tableau de myopathie est déterminé par la présence de plusieurs éléments. La faiblesse musculaire, la fatigue, la fatigabilité et l'asthénie, surtout proximales et symétriques des membres supérieurs et inférieurs (avec préservation des réflexes) sont principalement dues à l'altération musculaire, qu'elle soit structurelle (altération des fibres) ou fonctionnelle (altération du métabolisme). Les myalgies (douleurs musculaires) peuvent être associées à des crampes et des contractures. La crampe musculaire, contraction soutenue et douloureuse du muscle, est associée à une stimulation excessive et répétée du soma du motoneurone associé au muscle. Le manque de feedback négatif venant des organelles sensorielles de Golgi vu la fréquence élevée de stimulation empêche l'étirement spontané post-stimulation. La déshydratation est aussi une cause de crampe. L'étirement prolongé du muscle lors de la crampe envoie, via les récepteurs d'étirement, une information au SNC qui commande au muscle de se relâcher. La crampe fait partie au niveau physiopathologique des contractures.

La contracture est une contraction soutenue du muscle, elle est divisée en deux parties au niveau physiopathologiques, les contractures antalgiques compensatrices, ou la contracture est une solution à une douleur intense, les contractures algiques ou la douleur déclenche la contracture, et les contractures antalgiques et correspondantes aux rétractions. Au niveau électromyographique les contractures correspondent à des silences électriques pouvant durer plusieurs heures, surtout quand elles sont causés par des désordres métaboliques liés aux carbohydrates.

L'atrophie est une perte du volume musculaire, mais pour un même niveau de faiblesse le volume du muscle est mieux préservé dans les myopathies que dans les neuropathies, puisque dans les 
myopathies les fibres musculaires altérées sont remplacées par de la graisse et du tissu conjonctif. L'hypertrophie, au contraire, est une augmentation du volume musculaire, survenant en cas de myotonie, contraction soutenue non douloureuse. La surstimulation fréquente et élevée des fibres musculaires cause leur élargissement. Les patients atteints d'une myotonie vont avoir l'aspect de bodybuilder. Les myotonies se divisent en myotonies d'action, survenant après une contraction soutenue (serrer la main de quelqu'un) et en myotonie de percussion (utilisée pour le diagnostic en médecine). Les myotonies sont des contractions soutenues non douloureuses du muscle causées par une dépolarisation répétitive spontanées des membranes musculaires liées aux propriétés des membranes. Elles persistent en absence d'influx nerveux et elles sont favorisées par le froid et un repos prolongé en une posture fixe.

La pseudohypertrophie est un remplacement des fibres musculaires par du tissu conjonctif ou adipeux.

\section{Définition, Génétique, Physiopathologie et Clinique de la Dystrophie de Duchenne}

La dystrophie de Duchenne est une dystrophie musculaire héréditaire gonosomique récessive liée à $I^{\prime} X$ et touchant donc surtout les hommes. Elle est causée par la délétion de $70 \%$ du gène de la dystrophine, protéine permettant l'ancrage de l'actine au sarcolemme (bout $\mathrm{COOH}$ lié au sarcolemme et NH terminale lié à l'actine). La dystrophine est une protéine présente dans des nombreux tissus, comme le cortex cérébral, la rétine, les cellules de Schwann, foie, et les muscles squelettiques. Les patients synthétisent moins de $5 \%$ de dystrophine normales ce qui cause la pathologie.

La maladie débute le plus souvent entre l'âge de 3 et 5 ans ou l'enfant présente des difficultés à tenir le rythme de jeu avec d'autres enfants, tombe souvent, la course et les sauts sont anormaux. L'enfant doit s'aider de ses mains mettre ses jambes en position debout lorsqu'il se relève d'une position couchée. A partir de 5 ans la maladie est objectivée par une étude électromyographique. La faiblesse commence dans le membre inférieur au niveau proximal et remonte jusqu'au niveau respiratoire. Le patient se retrouve en chaise roulante environ à 12 ans. 
L'administration d'un oligonucléotide antisens PRO051 produit une omission de l'exon 51 durant l'épissage de l'ARN messager du gène de la dystrophine, facilitant l'expression d'une nouvelle dystrophine dans les fibres musculaires.

\section{Généralités des Dystrophies Myotoniques}

La physiopathologie de la myotonie est reprise au point 2.

Dans cette maladie, on a de manière générale une relaxation anormale lors d'une contraction ou percussion, ainsi qu'ne faiblesse des muscles de la face et des membres. Contrairement à la plupart des myopathies, l'atteinte musculaire est ici distale, et l'atteinte est multisystémique. Une cataracte, de la calvitie et une atrophie testiculaire (conduisant à l'infertilité) s'ajoute au tableau clinique.

\section{$\underline{5 .}$ Myotonie de type 1 ou maladie de Steinert}

La maladie de Steinert induit : une faiblesse, une fonte musculaire, une myotonie ainsi qu'une atteinte multi-système. Elle touche 1 personne sur 8000 naissances. Le chromosome impliqué est le chromosome 19. L'expansion d'un triplet aboutit au fonctionnement anormal de la myotonine protéine kinase. Cette protéine est exprimée dans différents tissus (cristallin, JNM, tendons, muscles) ce qui explique l'atteinte multi-système. L'expansion de triplets CTG (normal <30 mais ici > 40) va entrainer un fonctionnement anormal de la myotonine protéine kinase. De par l'expansion de triplets, on a une amplification avec une structure en boule au niveau de l'ADN. Il y a un phénomène d'anticipation (apparaît de plus en plus jeune au fur et à mesure des générations) et de potentiation (se manifeste de manière de plus en plus grave). Le nombre de triplet est généralement associé à la sévérité de la maladie. Dans la maladie de Steinert, lorsque le gène DMPK (dystrophine myotonine protéine kinase) est transcrit en ARN messager, l'expansion anormale de répétitions CTG qu'il comporte se retrouve aussi transcrite dans l'ARN messager. Trop long et formant sans doute des boucles anormales au niveau des répétitions, l'ARN anormal ne peut pas sortir du noyau et permettre la synthèse de la protéine DMPK. Les molécules d'ARN messager anormal s'accumulent dans le noyau en formant des agrégats dans lesquels certaines protéines nucléaires sont piégées. La présence de ces agrégats provoque des perturbations de l'expression de certains gènes. Les chercheurs ont ainsi 
découvert que certaines protéines n'étaient pas synthétisées sous leur forme adulte chez les personnes atteintes de la maladie de Steinert.

On observe une anomalie des canaux sodium voltage dépendant mais surtout une anomalie des canaux chlore. C'est précisément, l'anomalie des canaux chlore qui cause la myotonie.

Atteinte multi-système: elle présente un retard mental, des fractures fréquentes car anomalies osseuses, une cataracte, une atrophie des muscles de la face, une faiblesse des mains et des pieds (distale) et une atteinte cardiaque, principalement des troubles de la conduction, du rythme causé par une fibrose des tissus conducteurs et l'atteinte des myocytes.

Attention, l'atteinte cardiaque peut causer le décès. Donc ici on a une maladie dont le décès peut être causé par une «maladie» du cœur. Si faiblesse musculaire, toujours faire un ECG pour voir état du cœur. Si tachyarythmie, pose d'un pacemaker. Les malades de Steinert détestent l'hiver car la myotonie est favorisée par le froid. Le froid modifie l'excitabilité membranaire.

Pour le diagnostic (détecter le patient myotonique), on préférera réaliser un EMG qu'un test à la percussion car ce dernier n'est pas sensible à $100 \%$. Chez un patient myotonique on entend des bruits qui fluctuent, contrairement au patient normal (silence).

\section{Canalopathies}

Maladie génétique. La structure du muscle n'est pas atteinte. Les seuls éléments touchés sont les canaux. La caractéristique principale des canalopathies est l'apparition de myotonie ou de crampe. Ce sont des phénomènes intermittents: on parle d'accès de paralysie, parfois après un effort ou une période de repos, obligeant le patient à rester couché et ne pas bouger. Ces paralysies sont parfois accompagnées d’hyperkaliémie (anomalie canaux sodium situé sur le chromosome 17, autosomique dominant) ou d'hypokaliémie (altération canaux calciques de type $\mathrm{L}$, autosomique dominant) suivant les canaux touchés. Dans le cas de la paralysie hyperkaliémique le traitement est un diurétique tandis que dans le cas de paralysie hypokaliémique le traitement est bien évidemment une supplémentation en potassium. 


\section{$\underline{\text { 7. Maladies métaboliques }}$}

Il existe 3 catégories : 1) Anomalie du métabolisme des carbohydrates 2) Anomalie du métabolisme des lipides 3) Anomalies des mitochondries.

Exemple pour 1 : La maladie Mc Ardle (blocage de la glycolyse à cause de la déficience d'une enzyme, la phosphorylase musculaire ou myophosphorylase). Donc le patient est bon pour le marathon (quand apparition du second souffle: ok grâce au switch des lipides) mais pas bon pour sprint ou haltérophilie.

Exemple pour 2 : Déficit en carnitine palmitoyl transférase. Ici le contraire, on est bon en sprint et haltérophilie mais mauvais en marathon (car on ne sait pas utiliser la beta-oxydation).

Exemple pour 3 : On a donc une atteinte de la chaine respiratoire. Le déficit est tel ici que ces patients doivent utiliser la glycolyse anaérobie au repos ce qui entraîne une acidose lactique. On a souvent une atteint multi systémique (cerveau causant essentiellement des épilepsies, cœur, rein, muscles).

\section{Maladie de Pompe}

Maladie qui touche une personne sur 40000 naissances. Il existe 2 formes : une forme d'apparition précoce du nourrisson et une forme d'apparition tardive chez l'adulte (20-30-40 ans);

Maladie héréditaire autosomale récessive. L'anomalie génétique est localisée sur le chromosome 17. Cette mutation entraîne un dysfonctionnement de l'alpha-glucosidase acide (ou maltase acide) qui est une enzyme lysosomale responsable de la transformation du glycogène en glucose. Ce dysfonctionnement entraîne donc une accumulation de glycogène dans le muscle. On parle de glycogénose. La maladie de la Pompe est une des 50 maladies de surcharge lysosomale connues à ce jour. Cette maladie est donc un prototype des maladies lysosomales qui représentent un ensemble de 50 maladies rares et graves liées à un déficit enzymatique, lui-même secondaire à une mutation sur un gène. Ce déficit enzymatique entraîne une accumulation de substances non dégradées dans les lysosomes des différents organes. L'enzyme ici responsable est une enzyme chargée d'accélérer la transformation du glycogène en glucose dans les muscles : c'est l'alpha-glucosidase. Le glycogène est la forme de stockage des sucres essentiellement dans les muscles (fibres blanches) et le foie. L'alpha- 
glucosidase exerce sa fonction dans les lysosomes. Le glycogène n'est plus transformé et il s'accumule dans les lysosomes. Les lysosomes sont surchargés en glycogène: on parle donc de maladie de surcharge lysosomale. Ici comme il s'agit d'une accumulation de glycogène on parle de glycogénose.

Dans la forme infantile, le déficit de l'enzyme est presque total (moins de 1\% qui fonctionne normalement). Dans les formes tardives, le déficit est moindre (moins de 30\% fonctionnant normalement). La forme d'apparition précoce se caractérise chez le nourrisson par une hypotonie majeure et une cardiopathie sévère. En l'absence de traitement, l'évolution est généralement fatale lors de la première année de vie. Dans les formes d'apparition plus tardives, les symptômes peuvent débuter dès l'enfance, pendant l'adolescence ou à l'âge adulte. Ces patients présentent une faiblesse des muscles des membres, des muscles du tronc et des muscles respiratoires pouvant ainsi diminuer la capacité respiratoire. En l'absence de traitement, l'évolution lente conduit inexorablement vers un handicap moteur et/ou respiratoire nécessitant une aide à la marche et/ou une assistance ventilatoire mécanique. Si on parle de cette maladie rare, c'est parce qu'il existe un traitement. Le traitement consiste en une thérapie enzymatique substitutive, on réalise une perfusion d'une solution contenant l'enzyme de substitution. La perfusion répétée toutes les 2 semaines a permis d'améliorer les pronostics de survie. Si traitement de manière précoce : certains enfants ont pu refaire du sport après un passage en chaise roulante. Mais attention pas toujours une aussi grosse amélioration. 


\section{Maladies vasculaires cérébrales}

\section{Généralités, définitions et étiologies}

Les accidents vasculaires cérébraux (AVC) sont des pathologies fréquentes (130/100 000 habitants). Ce sont des pathologies graves (25\% des décès dans les jours ou semaines suivantes, 50\% handicapés, 25\% sans séquelles, 50\% dépression dans l'année, 25\% de démence dans les 5 ans) et complexes. Il s'agit d'un groupe de maladies dont les manifestations cliniques sont liées à une interruption du flux sanguin suite à une occlusion ou une rupture des vaisseaux. La taille de l'infarctus est en fonction de l'étendue de l'ischémie, de la durée et de la sévérité de l'accident. L'AVC peut être ischémique (occlusion par caillot) ou hémorragique.

Un accident vasculaire cérébral est défini par un déficit neurologique d'apparition brutale et de durée de plus de 24 heures causé par une cause vasculaire focale, contrairement à un accident ischémique transitoire, qui lui dure moins de 24 heures, les symptômes moins d'une heure et souvent ne montre pas de lésion à l’imagerie.

Les causes principales d'AVC sont l'athéromatose des gros vaisseaux, les maladies des petits vaisseaux, les embolies cardiaques ou artério-artérielles, les vasculopathies non athérosclerotiques (dissections, dysplasie fibromusculaire, anomalies héréditaires du tissu conjonctif, vasculites) et l’hypercoagulabilité.

\section{Physiopathologie de l'accident vasculaire cérébral}

La maladie thromboembolique se divise en embolie (chute brutale du flux sanguin) et thrombose in situ collatérale. Un caillot composé de fibrine, graisse, ou autre obstrue le flux vasculaire normal. La décompensation d'une maladie thromboembolique comprend une diminution de la perfusion proximale (chute de TA et du débit cardiaque), une augmentation des besoins métaboliques (fièvre, acidose, une dérivation du flux sanguin, un infarctus borderzone ou watershed (infarctus caractéristique situé à la jonction de deux territoires artériels différents.

La thrombose, obstruction du flux sanguin par un thrombus débutant du vaisseau, dont les causes peuvent être l'athéromatose, la dissection artérielle, la dysplasie fibromusculaire, le vasospasme 
(médicamenteux ou inflammatoire), les vasculopathies et les compressions tumorales. Les emboles sont générés par la paroi du vaisseau, peuvent provenir du cœur (fibrillation atriale), du système vasculaire, et peuvent être constitués d'air (embolie gazeuse), de cholestérol et de graisse (graisseuse), de cellules tumorales ou de matériel d'injection. La formation d'un thrombus est un modèle physiopathologique compliqué qui fait intervenir plusieurs agents: tout d'abord, une lésion de la paroi vasculaire (qui peut être induite, par exemple, par un dépôt de graisse dans la paroi) fait appel à la formation d'un dépôt de plaquettes, facteur tissulaire et fibrine. La dysfonction de l'endothélium, élément principale dans la régulation du flux sanguin (via des propriétés anti-athéromateuses et vasodilatatrices du monoxyde d'azote NO) induit un mécanisme pro-inflammatoire qui est prolifératif et procoagulant.

\section{Occlusion de la circulation antérieure}

\subsection{Artère cérébrale moyenne (ACM) ou artère sylvienne}

L'artère cérébrale moyenne $(\mathrm{ACM})$ vascularise via ses branches corticales la surface latérale de l'hémisphère cérébral à l'exception du pôle frontal et les stries supéromédiales du bord frontal et pariétal vascularisées par l'artère cérébrale antérieure (ACA) et les pôles occipitaux et pariétaux inférieurs vascularisés par l'artère cérébrale postérieure (ACP). Le segment M1 proximal donne des branches pénétrantes appelées lenticulostriées qui vascularisent le putamen, le globus pallidus externe, la partie postérieure de la capsule interne, la corona radiata et la plupart du noyau caudé. Dans la fissure sylvienne, l'ACM se divise en une branche M2 supérieure et une inférieure. L'inférieure vascularise le cortex temporal et pariétal inférieur, la supérieure vascularise le frontal et le pariétal supérieur. Une atteinte de l'ACM cause surtout une paralysie brachiofaciale contralatérale.

SI l'ACM est occluse à son origine bloquant les branches corticales et pénétrantes la présentation clinique comprendra une hémiplégie contralatérale, hémianesthésie, hémianopsie et regard dévié ipsilatéralement pendant quelques jours. La dysarthrie (difficulté à articuler des mots) est commune à cause de la faiblesse faciale. Des syndromes partiels du à l'occlusion d'une branche simple incluent des faiblesse de la main et/ou du bras, et faiblesse faciale avec aphasie non fluente de Broca. Une 
combinaison de dérangement sensoriel, faiblesse motrice et aphasie non fluente suggère que l'embole a occlus la branche proximale supérieure et l'infarctus s'étend largement sur les cortex frontal et pariétal. Une aphasie fluente de Wernicke est une manifestation de l'occlusion de la branche proximale inférieure vascularisant le cortex temporal de la sphère dominante. Une héminégligeance ou une agnosie spatiale sans faiblesse indique l'occlusion de la division inférieure vascularisant le cortex temporal et pariétal inférieur. Les occlusions des artères lenticulostriées produisent des AVC de la capsule interne, se manifestant par des syndromes sensorimoteurs ou moteurs purs. L'ischémie du genou de la capsule interne cause une faiblesse faciale suivie par une faiblesse du membre supérieur et inférieur lorsque l'infarctus s'étend dans le bras antérieur et le postérieur, avec une ataxie contralatérale et dysarthrie. L'infarctus lacunaire (des petits vaisseaux) qui affectent le globus pallidus et putamen se présentent avec peu de signes cliniques dont un parkinsonisme et un hémiballisme.

\subsection{Artère cérébrale antérieure (ACA)}

L'artère cérébrale antérieure (ACA) est divisée en deux segments: le segment A1 pré-artère communicante antérieure du polygone de Willis mettant en communication l'artère carotide interne avec l'artère communicante antérieure, et le segment A2 post-artère communicante antérieure. Le segment A1 donne naissance à des branches profondes qui vascularisent le bras antérieur de la capsule interne, les amygdales, l'hypothalamus antérieur, et la partie inférieure du noyau caudé. L'occlusion de l'ACA proximale est bien tolérée puisque l'artère communicante antérieure peut suppléer le sang contralatéralement. L'occlusion du segment A2 génère des signes tels que la paralysie du membre inférieur contralatéral (aire motrice du membre inférieur) avec perte de sensibilité (aire sensible du pied et de la jambe), incontinence urinaire (aire sensorimotrice dans le lobule central), reflexe de grasp contralatéral, aboulie (mutisme akinétique), lenteur, perte de réflexe, distraction par la vue et les sons (gyrus cingulé) et dyspraxie du membre gauche et aphasie tactile (corps calleux). 


\section{$\underline{4 .}$ Occlusion de la circulation postérieure}

\subsection{Artère cérébrale postérieure (ACP)}

L'artère cérébrale postérieure $(\mathrm{ACP})$ nait du tronc basilaire (1 $\mathrm{ACP}$ à gauche et une à droite). Elle participe au polygone du Willis donnant les artères communicantes postérieures, des artères perforantes, des artères pour le cortex visuel, pour la vascularisation postérieure du thalamus, l'hippocampe et une artère temporale antérieure. Elle est divisée comme pour l'ACA en un segment P1 avant l'artère communicante postérieure et un P2 après l'artère communicante postérieure.

Si le segment P1 est occlus, l'infarctus se situe au niveau subthalamique ipsilatéral, le thalamus médial, le pédoncule cérébrale ipsilatéral et le mésencéphale. Une atteinte du 3ème nerf sera présente, soit une ataxie contralatérale soit une hémiplégie contralatérale. Si le noyau sous-thalamique est atteint la manifestation clinique principale sera l'hémiballisme. Le syndrome de Déjérine consiste en une atteinte des artères thalamo-perforées et des artères géniculo-thalamiques se manifestant par une perte hémi-sensorielle contralatérale suivi d'une douleur brûlante et agonisante dans les zones concernées.

Si le segment P2 est occlus l'infarctus s'étend du lobe temporal médial et le lobe occipital. La manifestation fréquente est une hémianopsie homonyme avec épargne maculaire. Un défaut de mémoire passage peut être présent, il se résout puisque la mémoire est représentée de manière bilatérale. Si les deux ACP distales sont occluses les infarctus vont se manifester par le syndrome d'Anton, une cécité bilatérale avec réflexes préservés (et le patient peut ne pas se rendre compte de son défaut).

\section{Occlusion de la circulation vertébrale}

L'occlusion de l'artère vertébrale dans son premier segment (V1) présent de son origine jusque le 6 ${ }^{\text {ème }}$ foramen vertébral et le $4^{\text {ème }}$ segment (V4) qui participe avec l'artère vertébrale contralatérale pour former le tronc basilaire se manifeste par une ischémie de la moelle latérale, causant des vertiges, engourdissement des membres contralatéraux et de la face ipsilatérale, dysarthrie, dysphagie et un syndrome de Horner ipsilatérale. Cette manifestation clinique s'appelle se syndrome de Wallenberg. 


\section{Définitions, physiopathologie, sémiologie et électrophysiologie du syndrome pyramidal.}

Le syndrome pyramidal est l'ensemble des manifestations cliniques résultantes de l'atteinte, à quelque niveau que ce soit, de la voie cortico-spinale (faisceau pyramidal), support de la commande motrice volontaire. Pour rappel, la voie cortico-spinal regroupe en ipsilatérale le thalamus, le noyau pontin, le cortex moteur (ou la commande est générée) et frontal, en contralatéral le noyau denté, le cortex cérébelleux latéral, et arrive enfin à la moelle et les muscles. Le syndrome pyramidal se caractérise par des signes déficitaires (faisceau cortico-spinal) et des signes de spasticité (libération d'activités motrices réflexes normalement inhibés par la voie cortico-spinale, causés donc par une diminution des influx GABA et glycine). Le syndrome est controlatéral à la lésion lorsque celle si siège au dessus du bulbe, et ipsilatéral à la lésion si en dessous du bulbe. Les symptômes sont une faiblesse motrice (« paralysie »), sensation de contracture ou raideur liée à la spasticité, des troubles de la phonation et de la déglutition et des mictions impérieuses. En cas de lésion aiguë et étendue le déficit est massif, concernant un hémicorps. En cas de lésion partielle ou progressive, le déficit domine sur certains groupes musculaires en montrant une variété de signes : 1) au membre supérieur, l'épreuve du bras tendu montre une chute progressive du bras concerné par l'atteinte des muscles extenseurs et les mouvements alternés rapides sont difficiles (opposition pouce index) 2) au membre inférieur, l'atteinte des muscles fléchisseurs montre le signe de Mingazzini (chute progressive si le patient en décubitus dorsal tient ses cuisses fléchies et jambes à l'horizontale) et le signe de Barré (patient en décubitus ventral avec jambes fléchies à $90^{\circ}$ montre une chute progressive) 3) à la face, l'effacement du plis naso-génien et l'asymétrie lorsqu'on demande au patient de montrer les dents. La spasticité prédomine sur les fléchisseurs au membre supérieur et les extenseurs au membre inférieur, s'accentuant à l'action et pouvant parfois être douloureuse. Lors d'une étude électrophysiologique, l'hypertonie développée se manifestera par une augmentation de la réponse $H$ pour une même stimulation. Un autre signe présent est celui de Babinski : extension de l'hallux du pied lorsqu'il est stimulé à l'aide d'un objet sur le bord extérieur (tandis que la réponse normale serait une flexion ; 
attention ce reflexe n'est pas développé chez les enfants donc test inutile). Le traitement de la spasticité se fait via du GABA A (baclofen) ou GABA B (diazépam).

\section{$\underline{7 \text { Prise en charge des accidents vasculaires cérébraux et leur importance : TIME IS BRAIN }}$}

Le délai essentiel de la prise en charge d'un AVC chez un patient est de $3 \mathrm{~h}$ : il est expliqué par le fait que 30\% (seuil critique) des AVC se compliquent au delà de ce délai. La réperfusion de la zone atteinte se fait en effectuant une thrombolyse du caillot obstruant la zone. La thrombolyse s'effectue via Alteplase (Actilyse $\left.{ }^{\circledR}\right)$, une molécule recombinante identique à l'activateur du plasminogène (rt-PA). L'agoniste de l'activateur du plasminogène active le système fibrinolytique qui cause la lyse du caillot, mais ne peut être utilisé que dans un délai de 3h après l'obstruction, sauf si lésion très étendue (contre-indication). Une surveillance est nécessaire puisque un switch peut s'observer entre un AVC ischémique et hémorragique. Le NNT de ce traitement (nombre de patient à traiter pour en guérir 1) est de 8. L'aspirine, inhibiteur de la cycloxygénase (en inhibant l'agrégation plaquettaire via une diminution du thromboxane A2) peut être donnée en prévention d'un AVC chez un patient à risque. Une chirurgie de décompression sert à ouvrir un volet crânien pour que la partie sous-jacente de cerveau qui est en train d'enfler puisse avoir de la place pour le faire sans pour autant causer un engagement. Une fois la phase aiguë passée, le crâne peut être fermé. 


\section{Céphalées}

\section{Généralités, définitions et épidémiologie}

Les céphalées regroupent toute plainte douloureuse provenant de la région crânienne. Elles font partie des dix causes les plus fréquentes de consultation dans une pratique de médecine générale et de $16 \%$ des motifs de consultation aux urgences. Selon la classification internationale des céphalées elles sont regroupées en céphalées primaires, secondaires et névralgies crâniennes ou faciales.

\section{Anatomie et physiologie de la céphalée (la « théorie neurogène »)}

Les nocicepteurs périphériques sont stimulés en réponse aux dégâts tissulaires, distension viscérale ou autres facteurs. Les nocicepteurs peuvent aussi être activés lorsque les signalisations de la douleur sont endommagées ou stimulées de manière inappropriée. Les structures intervenant dans la céphalée primaire sont les vaisseaux intracrâniens de grandes dimensions, la dure mère ainsi que les branches du nerf trijumeau l'innervant, la portion caudale des ganglions du nerf trijumeau qui forment avec la corne dorsale de la moelle le complexe trigéminal, les structures dorsales du traitement de la douleur telles que le thalamus ventropostéromédial (VPM) et le cortex, et les systèmes de modulation de la douleur à tout niveau. En stimulant le reflexe autonome trigéminal via son complexe, surtout via le V1 nerf ophtalmique on peut déclencher une vasodilatation des vaisseaux crâniens et donc une inflammation neurogène. Cette vasodilatation véhiculée par le Vasoactive Intestinal Peptide (VIP, mais d'autres peptides peuvent participer, comme la substance P ou le CGRP, dans ce cas ci la vasodilatation sera véhiculée par lé sérotonine mais aussi l'histamine, les prostaglandines, la bradykinine) participe à la douleur physiologique de la céphalée. Cette douleur est nociceptive, donc due au fonctionnement normal des récepteurs. Les neurones du V sont par la suite sensibilisés.

\section{$\underline{3 .}$ Evaluation clinique de la céphalée aigue}

La probabilité de trouver des causes sérieuses chez un patient atteint de céphalée aigue pour la première fois est beaucoup plus élevée que chez un patient atteint de céphalées récurrentes et chroniques depuis plusieurs années. Les causes à évaluer le plus rapidement possible sont la méningite, l'hémorragie sous arachnoïdienne, hématome sous-dural ou épidural, glaucome, tumeur 
ou sinusite purulente. L'interrogatoire doit distinguer le patient en le classifiant en 4 catégories: céphalée récente à début soudain, céphalée récente d'aggravation progressive, céphalée chronique paroxystique et céphalée chroniques quotidiennes. Un examen neurologique complet est une première étape essentielle, et comprend la recherche de raideur méningée, des signes de focalisation, l'examen des pupilles, de l'acuité et du champ visuel ainsi que l'examen du fond de l'œil. Si des anomalies sont découvertes le bilan doit être complété par un scanner ou une IRM, et parfois une ponction lombaire. L'évaluation psychologique est aussi importante puisque la dépression est parfois associée à une lésion crânienne.

\section{Céphalée primaire}

\section{$\underline{4.1 \text { Migraine }}$}

La migraine est deuxième cause la plus fréquente de céphalée touchant $15 \%$ des femmes $(1 / 4$ des femmes dans la quarantaine) et $6 \%$ des hommes. Il s'agit d'une céphalée épisodique associée à de la sensibilité à la lumière, le son ou le mouvement; elle est parfois accompagnée de nausées et/ou vomissements. La migraine peut être souvent reconnue par des éléments déclenchants (triggers), pouvant être des stimuli sensoriels et environnementaux: les patients atteints de migraines ne s'adaptent pas facilement aux stimuli sensoriels. La migraine est une douleur neuropathique, donc due à un dérèglement des structures normales de la perception de la douleur. Le dysfonctionnement des systèmes de contrôle monoaminergique situé dans le thalamus et le tronc cérébral est à l'origine de ce type de céphalée. Dans ce cas, le peptide lié au gène de la calcitonine (CGRP) stimule les ganglions trigéminaux en activant leurs extrémités vasculaires. Les antagonistes de CGRP comme l'olcegepant ou le telcagepant ou encore des anticorps monoclonaux se sont démontrés efficaces pour le traitement des migraines. La sérotonine se fixant sur les récepteurs 5-HT est aussi impliquée dans les migraines; lors de migraines récidivantes au traitement antidouleur classique (paracétamol) le médecin généraliste ou spécialiste pourra prescrire des triptans (sumatriptan ou almotriptan par exemple), des antagonistes du récepteur 5-HT1. 
Les migraines sont divisées en migraine avec ou sans aura. L'aura est un symptôme neurologique focal transitoire : des troubles visuels, sensitifs ou du langage survenant avant le début de la céphalée. Ce phénomène d'irritation et/ou de déficit neurologique sont réversibles et ont la particularité de s'installer et de régresser en quelque minutes et non de façon brutale. Pour le diagnostic d'une migraine sans aura il faut que deux des critères suivants soient rempli dans au moins 5 crises: céphalées unilatérale, pulsatile, modérée ou sévère, aggravation par les activités physiques simples ; la céphalée doit ensuite durer entre 4 et 72h sans traitement, et aussi qu'elle soit accompagnée de nausée et/ou vomissement ou par de la photophobie et phonophobie. Pour le diagnostic de migraine avec aura il faut qu'au moins une des caractéristiques entre troubles de la vision (positif ou négatif), paresthésies/hypoesthésies ou aphasie soient remplis ; au moins deux des critères entre symptômes visuels homonymes et/ou sensitifs unilatéraux, une ou différentes aura présente sur plus de 5 minutes, chaque symptôme durant entre 5 et 60 minutes ; la céphalée doit enfin débuter pendant ou 60 minutes après l'aura.

Une migraine comporte différentes phases qui se succèdent: une phase de prodromes, une phase d'aura, une phase neurovasculaire et une phase de rétablissement spontané. Les complications peuvent survenir: le status migrainosus est un prolongement de $72 \mathrm{~h}$ des maux de tête; on peut parfois développer une migraine persistante suite à un abus de médicament (cercle vicieux); un infarctus migraineux est le développement d'un AVC pendant l'aura.

\subsection{Migraines hémiplégique familiale}

Maladie autosomique dominante due à une mutation du gène CACNA1A du chromosome 19 altérant des canaux calcium, ou du gène codant pour la NaKATPase du chromosome 1.

\section{$\underline{4.3 \text { Cerebral Autosomal Dominant Arteriopathy with Subcortical Infarcts and Leukoencephalopathy }}$}

Maladie autosomique dominante causée par une altération du gène Notch 3 sur le chromosome 19. Dans cette pathologie des petits vaisseaux, des petits infarctus fréquents sont présents qui altèrent le fonctionnement normal des nocicepteurs. 


\subsection{Céphalées en grappe (Cluster headache)}

Les céphalées en grappe sont une forme rare de céphalée avec une fréquence de $0.1 \%$ dans la population. Il s'agit d'une douleur très intense profonde, rétro-orbitaire et unilatérale persistante 15 à 180 minutes en l'absence de traitement (moyenne une heure), et présentant au moins un parmi les phénomènes d'œil rouge, larmoyant, nez bouché ou rhinorrhée, sudation du visage ou du front, myosis, ptosis, œdème des paupières. La fréquence des crises varie de 1 tous les 2 jours à 8 chaque jour.

\subsection{Hémicrânie paroxystique chronique}

Elle touche essentiellement la femme, sa fréquence est d'au moins 5 crises/jour de 2 à 30 minutes. Unilatérales, elle touche la région orbitaire et répond de façon absolue à l'indométacine (AINS, l'épreuve thérapeutique consiste à donner de l'indométacine $3 \times 25 \mathrm{mg} / \mathrm{j}$ pendant $48 \mathrm{~h}$ suivi de 3x50 $\mathrm{mg} / \mathrm{j}$ si réponse nulle ou insuffisante, puis traiter avec dose d'entretien la plus petite possible).

\subsection{Céphalées de tension}

Les céphalées de tension représentent $2 / 3$ des céphalées primaires. Elles se présentent soit sous une forme épisodique rare (12 par an, soit 1 épisode par mois), soit épisodique fréquente (entre 12 et 180/an, soit 15 par mois). Elles sont dues à un déséquilibre du contrôle de la douleur dans le système nerveux central. Elles ont une allure bilatérale.

\section{$\underline{4.7 \text { Névralgie du Trijumeau }}$}

Il s'agit de décharges électriques dans le territoire d'une ou plusieurs branches du trijumeau. Les névralgies du V sont caractérisée par un élément déclenchant ou trigger (mastication, brossage des dents). Elles touchent 3 femmes pour 1 femme, peuvent être idiopathiques (unilatérales le plus souvent), symptomatiques ou associées au spasme facial (associée à une tumeur, le plus souvent un cholestéatome, un anévrisme ou une malformation artérioveineuse). 


\section{Céphalée secondaire}

Les céphalées secondaires sont dues à d'autres pathologies sous jacentes, donc le traitement va se focaliser sur la pathologie primaire: elles peuvent être dues à des méningites, des hémorragies intracrâniennes, des tumeurs cérébrales, des artérites temporales et des glaucomes. 


\section{Coma et états de conscience altérée}

\section{Généralités}

Le coma est un des problèmes les plus communs en médecine générale et aux urgences ; il demande dans l'immédiat une approche organisée et structurée. Il y a un certain nombre d'états à alerte réduite, le plus sévère étant le coma, défini comme un état similaire à un sommeil profond duquel on ne pourra pas réveiller le patient. Le sommeil est quant à lui, un état de conscience réduite physiologiquement réversible (si stimulus adéquat, donc différent du coma) et récurrente, ou la réactivité des systèmes du tronc ainsi qu'aux stimuli environnementaux est réduite La stupeur est un état d'excitabilité temporaire dans lequel le patient peut être réveillé temporairement si soumis à des stimuli très vigoureux. La somnolence est un état de sommeil léger qui est caractérisé par une excitabilité facile et la persistance d'alerte pendant des brèves périodes. La somnolence et la stupeur sont accompagné le plus souvent d'une confusion. L'état végétatif est l'état de réveil mais de non réponse dans lequel se trouve un patient qui vient de sortir du coma. Certaines réponses motrices peuvent persister mais peu d'entre elles ont du sens. Les fonctions respiratoires et autonomes sont conservées. L'état de conscience minimale est plus léger que l'état végétatif et peut inclure des réponses vocales ou motrices souvent volontaires et même une réponse à une commande. Le locked in state représente un état d'éveil ou le patient est incapable de produire des sons ou des mouvements mais garde les mouvements oculaires verticaux, il peut donc communiquer via code Morse. Le locked in state est causé par un infarctus ou une hémorragie de la voie corticospinale et corticobulbaire. Après un mois d'état végétatif les probabilités de regagner les facultés mentales sont proches de zéro, et $c^{\prime}$ est à ce moment qu'on définira l'état végétatif persistant. La possibilité d'attribuer une fausse signification à des mouvements faits par le patient est souvent source de souffrance pour la famille dans le cas ou les fonctions cérébrales restent absentes. La conscience normale dépend d'un cerveau intact. Une perte de conscience est un symptôme d'une défaillance cérébrale, le cerveau possède une tolérance limitée aux agressions physiques ou métaboliques. 


\section{Anatomie et physiologie du Coma, du sommeil, des états de conscience normale et altérée}

Toute altération de l'état de conscience normale est due à une atteinte du cortex ou au système thalamocortical qu'est la réticulée ascendante activatrice ou système activateur réticulé, située dans le mésencéphale, en particulier le noyau pédonculo-pontin et noyau cunéiforme ; leur rôle est celui d'hyperpolariser les noyaux réticulaires du thalamus lui empêchant de stimuler les cortex. Toute lésion physique de la réticulée ascendante dans sa portion mésencéphalique ou lésion des cortex bilatéralement ou suppression de la fonction du système réticulé via des toxines, drogues, dérangements métaboliques cause l'altération de l'état de conscience. Un engagement cérébral peut aussi causer une altération de l'état de conscience par compression de la formation réticulée : il peut être de type temporal, sous falcoriel (sous la faux du cerveau), central, et via le trou occipital (foramen magnum).

Le sommeil est crucial pour la préservation de notre santé : il s'alterne de cycle REM (mouvements oculaires rapides) et non REM à des intervalles de 90 minutes. Les rêves se succèdent dans la phase REM, ou la personne peut aussi avoir une respiration et un rythme cardiaque irréguliers, une érection pénienne ou clitoridienne et une hypotonie des muscles squelettiques et des voies aériennes. La phase REM est caractérisée par un EEG désynchronisé, comme dans l'éveil. Les circuits induisant le sommeil REM sont la formation réticulée ascendante activatrice (FRAA) cholinergique très active, le système monoaminergique se projetant sur le cortex non actif, l'augmentation de l'activité thalamocorticale (mais cortex non réceptif) et l'activation des neurones dans la région du Locus Coeruleus projetant sur le tronc et la moelle générant des atonies et des mouvements oculaires. Les antidépresseurs augmentant le taux de sérotonine et noradrénaline diminuent les phase REM, les voies monoaminergiques augmentent donc l'éveil. Le thalamus quant à lui gère le sommeil non REM.

Deux autres noyaux intervenant dans l'éveil/sommeil sont le noyau tubéromammilaire fonctionnant à l'histamine diffusant sur le cortex (ce qui explique l'effet sédatif des antihistaminiques) et les noyaux hypothalamiques latéraux à l'Orexine (stimulant la FRAA) ou le GABA. 


\section{Mécanisme Flip/Flop}

Modèle d'interaction inhibitrice réciproque ou «flip-flop switch» entre les systèmes d'éveil et de sommeil. Pendant le sommeil, les neurones de la VLPO (aire ventrolatérale pré-optique) sont actifs et inhibent les neurones d'éveil, monoaminergiques. De la même manière, pendant l'éveil, ces derniers inhibent les neurones de la VLPO. L'orexine joue un rôle modulateur sur cet équilibre: les neurones qui libèrent ce neuropeptide sont actifs pendant l'éveil et renforcent le tonus monoaminergique. On comprend donc pourquoi un déficit en orexine (qui sert à inhiber le sommeil REM) peut induire une narcolepsie. Du fait du déficit en orexine, il y a un défaut dans la transition veille/sommeil.

Il y a un système FLIP/FLOP qui gère le passage veille/sommeil. La transition entre les 2 est de très courte durée car on inhibe le système qui inhibe : on parle d'autorenforcement. La découverte de l'orexine et la démonstration de son implication dans la narcolepsie soulignent l'importance physiologique d'un contrôle efficace des transitions entre la veille et le sommeil. Il existe un mécanisme analogue de flip-flop dans le passage NON REM/REM mettant en jeu aussi l'orexine; les neurones REM OFF sont inhibés et stimulés respectivement par le GABA et l'orexine alors que le locus Coeruleus stimule les neurones REM ON. On comprend dès lors aisément pourquoi un déficit d'orexine peut causer une cataplexie. C'est du à un problème dans la transition NON REM/REM qui explique la paralysie soudaine.

\section{Narcolepsie et cataplexie}

La découverte de l'orexine et la démonstration de son implication dans la narcolepsie et cataplexie soulignent l'importance physiologique d'un contrôle efficace des transitions entre veille/sommeil (narcolepsie) et NON REM/REM (cataplexie). En résumé, les mécanismes de FLIP-FLOP veille/sommeil et NON REM/REM sont tous les 2 perturbés par un déficit en orexine, ce qui explique respectivement la narcolepsie et la cataplexie (il s'agit d'un trouble du sommeil chronique qui est caractérisé par un temps de sommeil excessif). La narcolepsie est due à une diminution de l'activité des neurones à orexine qui provoque un passage très rapide en sommeil REM lors de l'endormissement. Cette diminution d'orexine peut être due à un mécanisme auto-immun. Lors de la 
vaccination du virus H5N1 (virus influenza, aussi association à certain groupe HLA), certains cas de patients narcoleptiques ont été recensés. Il y a en effet eu destruction des cellules à orexine par réaction auto-immune. Donc les patients narcoleptiques s'endorment n'importe où et n'importe quand et directement en phase REM sans sommeil lent qui précède. Un deuxième signe clinique est souvent associé à la narcolepsie : la cataplexie qui est une perte réversible de tonus musculaire de brève durée et sans perte de conscience. Ces 2 symptômes ne surviennent pas nécessairement en même temps. La maladie de Gelineau est une maladie génétique (mais avec les mêmes symptômes que la cataplexie) touchant les hommes jeunes qui s'explique par un problème au niveau de la gestion du sommeil paradoxal. Présence de 2 symptômes : narcolepsie et cataplexie. Le patient s'endort en sommeil paradoxal et souffre de paralysie soudaine, les deux ne survenant pas nécessairement en même temps. La cataplexie peut être déclenchée par des émotions vives.

\section{Coma}

\section{$\underline{5.1 \text { Généralités }}$}

On retrouve 3 critères communs au coma et au sommeil : altération de l'état de conscience, EEG à activités lentes de haut voltage, perte d'activité de la FRAA. Dans le sommeil, il s'agit d'une inhibition régulée. En présence de stimulation, on se réveille (=l'éveil). Quant au coma, présence de lésions avec altérations des cycles REM/NON REM. Il existe trois types de causes au coma :

1. Causes symétriques non structurelles:

- Toxiques (alcool)

- Drogues (benzodiazépines, opiacés)

- Métaboliques (hypocalcémie, hypoglycémie du diabétique)

- Infections (bactéries, virus, parasites)

- Autres : post-ictal (après la crise d'épilepsie, on a un petit coma

2. Causes symétriques structurelles : lésions (lésion de la réticulée)

3. Causes asymétriques structurelles : lésions (AVC localisé à un hémisphère) 
Autrement dit, les lésions peuvent être :

1. Structurelles :

- diffuses multiples (nombreuses dans tout le cerveau)

- focales (au niveau du tronc cérébral)

2. Métaboliques

- défaut dans l'apport de glucose

- défaut dans l'apport en oxygène

- diminution du flux sanguin cérébral

Lors d'un gros AVC, le cerveau étant dans une boîte crânienne non extensibles, les parties saines vont se déplacer provocant ce qu'on l'on appelle un engagement. Ces engagements sont donc aussi une des grandes causes de coma. Ces engagements sont de 4 types : temporal, sous falcoriel (sous la faux du cerveau), central, trou occipital (foramen magnum). L'engagement temporal provoque souvent la compression du nerf crânien III (oculomoteur commun). Ce nerf crânien étant mixte, il conduit aussi du parasympathique ce qui explique l'apparition d'une mydriase qualifiée de mydriase aréflective (augmentation du diamètre de la pupille : mydriase est le contraire du myosis). Il faut savoir que la mydriase est due à l'activation du système orthosympathique ou à l'inhibition du système nerveux parasympathique. Ici c'est de l'inhibition du parasympathique dont il s'agit. L'évaluation de l'état de conscience se fait par un examen clinique qui comprend : niveau de conscience à la réponse verbale, respiration, pupilles (taille et réactivité), mouvement oculaires, réponses motrices. L'observation des pupilles permet de vérifier d'éventuelles lésions de l'oculomoteur commun et de juger de l'état du mésencéphale. Vu que le nerf crânien VI oculomoteur externe ou abducens est le nerf crânien avec le plus long trajet intracrânien, il sera immanquablement victime de lésion lors de lésions cérébrales. Une évaluation des mouvements oculaires est donc opportune pour juger l'état de la lésion. Cet examen peut se faire de 2 manières : soit on tourne la tête du patient et normalement on doit observer un mouvement des yeux dans la directement opposée au mouvement de la tête. Une autre technique plus souvent utilisée surtout dans les cas où le patient souffre d'une fracture au niveau cervical, est 
l'utilisation d'eau chaude et d'eau froide. La respiration est également importante à examiner. Le pattern le plus connu est la respiration de Cheynes Stokes: c'est une respiration rapide et très profonde puis suivie d'une pause. Cette alternance est due au retard de communication entre les poumons et le centre respiratoire (si altération du flux, on augmente le risque d'avoir une respiration de type Cheynes Stokes. Dans un coma, le sujet présente les caractéristiques suivantes: sujet non réactif, allongé, les yeux fermés, insensible aux stimuli, grimaces si stimuli douloureux (mouvements réflexes), présence de retraits réflexes pouvant disparaitre si le coma s'aggrave, perte des cycles normaux de sommeil, de la conscience et d'éveil (ni conscience ni éveil).

\section{$\underline{5.2 \text { Causes structurelles du Coma et physiopathologie }}$}

Lésions structurelles : peuvent être diffuses multiples (nombreuses dans tout le cerveau) ou focales (au niveau du TC) ;

L'engagement : temporal, sous-falcoriel, central ou par le foramen magnum (le cerveau est une structure fragile, qui se comprime, dans une boîte osseuse rigide, un hématome ou une tumeur peut refouler les structures cérébrales, qui peuvent pousser sur le tronc cérébral et interrompt les influences de la FRAA formation réticulée ascendante activatrice, lésion conduisant à l'inconscience).

Un AVC dans le tronc cérébral : si on lèse la FRAA, on sera dans le coma, même si le cortex est intact (si les fibres sont lésées mais pas la FRAA, le patient peut avoir un Locked-in State).

\section{$\underline{5.3 \text { Causes métaboliques et physiopathologie }}$}

Lésions métaboliques :

a) défaut dans l'apport de glucose

b) défaut dans l'apport en oxygène

c) diminution du flux sanguin cérébral entraînent une diminution des 2 éléments cidessus.

Flux sanguin cérébral : d'environ $55 \mathrm{ml} / 100 \mathrm{~g} / \mathrm{min}$ au repos, est 3 à 4 fois plus important dans la substance grise que dans la substance blanche. Le flux varie en fonction de l'activité d'une zone pour 
satisfaire ses besoins : la consommation de glucose augmente de $\pm 50 \%$ dans la zone activée alors que la consommation d'oxygène augmente de $\pm 5 \%$ dans la zone activée.

Apport en glucose: la glycémie normale est supérieure à $60 \mathrm{mg} / \mathrm{dl}$; EEG pendant coma hypoglycémique donne des ondes lentes différent d'un EEG avec une glycémie normale ; ici ce sont les 2 hémisphères qui ne fonctionnent pas bien: il y a une activation lente et diffuse des 2 hémisphères. La réticulée est intacte. Pas de lésion dans ce cas.

Ischémie - hypoxie : un apport de $20 \mathrm{ml} / 100 \mathrm{~g} / \mathrm{min}$ entraine une perte de conscience mais pas de dommages permanents. Un apport inférieur à $10 \mathrm{ml} / 100 \mathrm{~g} / \mathrm{min}$ entraine des dommages irréversibles (perte de l'intégrité membranaire, mort cellulaire, accumulation de Ca). La gravité dépend du temps d'ischémie. Plus ça dure, plus l'acidose lactique et l'hypoglycémie sont importantes ce qui va causer la perte de neurones.

Ischémie globale : la perte de connaissance se présente à partir de 20 secondes d'hypoxie, à partir de 5 minutes d'hypoxie la perte neuronale commence : épuisement du glucose et des réserves d'ATP, dépolarisation, relargage de glutamate, entrée de Ca dans la cellule. Même s'il y a une réanimation après ce laps de temps, il y aura des séquelles sévères. Attention aux lésions de réperfusion du à l'altération de la barrière hématoencéphalique induite.

Pour terminer, les structures touchées lors d'une ischémie :

- atteinte bilatérale massive ;

- neurones des couches 3 et 5, région CA1 de l'hippocampe

- accumulation de ca et glutamate (cf. AVC)

- $\quad$ apoptose (cf. AVC)

- nécrose pseudolaminaire (nécrose qui s'installe au niveau du cortex) 


\subsubsection{Coma métabolique du à l'Intoxication au CO.}

Le monoxyde de carbone (CO) est un gaz inodore, insipide, non irritant, plus léger que l'air, dont la concentration atmosphérique est inférieure au $0,001 \%$ et dont la concentration létale est inférieure à 0,1\%. La production de Co peut être endogène qui résulte du catabolisme de l'hémoglobine (taux sanguin de carboxyhémoglobine : $\mathrm{HbCO} 1$ à 3\%) ou exogène lors de combustion incomplète (le plus souvent du à des appareils défectueux avec mauvaise évacuation). L'intoxication aiguë au CO s'explique par différents mécanismes physiopathologiques : tout d'abord, une résorption pulmonaire, voie d'entrée ou de sortie du CO, en suite le développement d'une hypoxie (due à la diminution du transport en O2), où la liaison compétitive avec hème de l'hémoglobine déplace la courbe de dissociation de l'hémoglobine vers la gauche (moins d'oxygène transporté qui cause l'hypoxie) donc l'affinité pour l'O2 pour que l'hémoglobine augmente ; enfin une toxicité cellulaire par le CO dissout (1\%) se liant à la myoglobine, interagissant avec les cytochromes mitochondriaux et causant une hyperoxydation lipidique qui peut donner une démyélinisation.

L'intoxication au CO peut donner un développement neuropsychiatrique tardif : c'est un phénomène mal connu, qui peut se développer 3 à 240 jours après l'épisode aigu (intoxication au CO), caractérisé par des troubles cognitifs fins (troubles de la personnalité, Parkinson, démence, psychose).

Le traitement de l'intoxication au $\mathrm{CO}$ se résume à l'éviction immédiate de la zone riche en $\mathrm{CO}$, un traitement symptomatique et un traitement à l'oxygène (puisque la demi-vie de l'HbCO est de $6 \mathrm{~h}$ à l'air ambiant, $1 \mathrm{~h} 30$ à 100\% d'O2 dans masque, 20 min en caisson hyperbare (3 atm)

Dans intoxication sévère au $\mathrm{CO}(\mathrm{HbCO} 25$ à 40\%), l'oxygénothérapie hyperbare est fortement indiquée. 


\subsubsection{Correction trop rapide d'une hyponatrémie et myélinolyse centropontique}

L'osmolarité normale est situé aux alentours de $290 \mathrm{mEq} / \mathrm{L}$. Si l'osmolarité est inférieure à 260 ou supérieure à $330 \mathrm{mEq} / \mathrm{L}$ des signes neurologiques peuvent apparaître. Si hyponatrémie aigue, les mécanismes protecteurs contre les modifications d'osmolarité peuvent être dépassé.

Etapes chronologiques :

1. Hyponatrémie aigue

2. Entrée d'eau dans le cerveau aboutissant à une osmolarité basse dans le cerveau

3. Adaptation rapide du cerveau par perte des osmoles minérales (NA, $\mathrm{K}, \mathrm{Cl}$ )

4. Adaptation lente du cerveau par perte des osmoles organiques (glutamate, glutamine)

5. Soit correction adéquate et retour à une osmolarité normale du cerveau soit correction trop rapide et démyélinisation osmotique : on parle de myélinolyse centropontique.

La correction se fait par ingestion de $\mathrm{Na}+$ et restriction hydrique.

Si la correction est trop rapide, le patient risque une démyélinisation osmotique (myélinolyse centropontique) et donc un coma.

\subsubsection{Correction trop rapide d'une hypernatrémie et œdème cérébral}

Dans le cas d'une hypernatrémie aigue, les mécanismes protecteurs contre les modifications d'osmolarité peuvent être dépassés. Etapes chronologiques :

1. Hypernatrémie aigue

2. Sortie d'eau du cerveau aboutissant à une osmolarité élevée dans le cerveau

3. Adaptation rapide du cerveau par accumulation des osmoles minérales ( $\mathrm{NA}, \mathrm{K}, \mathrm{Cl}$ )

4. Adaptation lente du cerveau par accumulation des osmoles organiques (glutamate, glutamine)

5. Soit correction adéquate et retour à une osmolarité normale du cerveau soit correction trop rapide et oedeme cérébral.

La correction se fait par ingestion hydrique. Attention si on donne trop vite trop d'eau, le cerveau va tout prendre. Dans des situations catastrophiques, on a recours au mannitol qui crée une 
hyperosmolarité en périphérie mais attention à l'effet rebound quand le mannitol sera petit à petit éliminé. Si la correction est trop rapide, cela entraine un œdème cérébral pouvant causer la mort par engagement.

\section{Etat de conscience minimale}

Définition: L'état de conscience minimale est une altération de la conscience dans laquelle est démontrée une perception du soi et de son environnement. Le patient présente des réponses reproductibles à la commande, peut suivre des yeux un objet de manière soutenue, peut aussi communiquer de manière élémentaire mais adéquate (mouvement de tête signifiant oui/non : code verbal), peut manifester des comportements émotionnels adaptés.

Il est important de souligner que les réponses sont fluctuantes (varient au cours de la journée ou d'un jour à l'autre), la réponse à une stimulation peut nécessiter une sollicitation importante et répétée, cette réponse doit être reproductible avant de conclure à une action volontaire.

Récupération éventuelle : des réponses sont de plus en plus consistantes, le patient sort de l'état de conscience minimale lorsqu'il est capable de communiquer de manière fonctionnelle.

Les chances de récupérer sont meilleures qu'en état végétatif mais certains patients peuvent rester de manière prolongée dans cet état. La perception de la douleur est aussi quelque chose d'important dans l'état de conscience minimale, il y a des activations corticales prouvant que le patient est capable d'intégrer la douleur. De même, il est capable de penser qu'il joue au tennis si on lui demande ou de penser qu'il se déplace dans sa maison. Une stimulation intracérébrale au niveau du thalamus central chez un patient en état de conscience minimal améliore ses fonctions cognitives, sa mobilité ainsi que sa prise alimentaire.

\section{Etat végétatif}

L'état végétatif est souvent dû à une atteinte globale du cortex ou de la substance blanche, ou plus rarement, d'une lésion thalamique bilatérale avec préservation de la substance réticulée (si on interrompt communication entre réticulée et hémisphères cérébraux). Les caractéristiques sont :

- Préservation des fonctions autonomes (régulation cardiovasculaire, thermorégulation) 
- Préservation des cycles veille-sommeil (épisodes d'ouverture spontanée des yeux) différent du coma

- Pas de réponse à la commande verbale, pas d'interaction avec lui

- Le patient ne parle pas, ne produit aucun mot mais peut émettre des grognements

- Rires, pleures, ou grimaces dans certains cas et sans raisons apparentes, sans adéquation (cela vient de manière aléatoire)

Aucun comportement n'est volontaire et dirigé dans un but précis. Il n'y a aucun signe de conscience mais une persistance de comportements réflexes.

Pronostic est déterminé par test des potentiels évoqués somesthésiques du nerf médian : on stimule le nerf médian et si absence de réponse il n'y a aucune chance de récupération, les conséquences possibles sont le décès ou une mauvaise récupération (état végétatif persistant).

\section{Encéphalopathie de Wernicke}

Cette pathologie est causée par une carence en thiamine (vitamine B1) qui peut trouver son origine dans :

1. Malnutrition chez les alcooliques ;

2. Vomissement intense (femme enceinte ou pathologie digestive)

Elle induit des dommages irréversibles si non traitée à temps dont des lésions

1. Diencéphaliques

2. Périaqueducales (tronc cérébral)

Le patient atteint d'une encéphalopathie de Wernicke présente :

1. Confusion, somnolence et très rarement un coma

2. Ophtalmoplégie (paralysie des yeux)

3. Nystagmus

4. Ataxie

5. Dysarthrie (difficulté à articuler) 
Elle provoque une accumulation de glutamate et de la décarboxylase de l'acide glutamique dans les tissus par passage à travers les vaisseaux sans barrière hémato-cérébrale et diffusion dans les régions contiguës (diencéphale et tronc cérébral). Ceci aboutit à une toxicité qui cause cette encéphalopathie de Wernicke. Donc la thiamine est importante pour le transport ionique dans les terminaisons nerveuses, pour la régénération et le maintien du potentiel d'action mais intervient aussi dans le métabolisme du glucose. Ceci explique pourquoi en cas d'hypoglycémie couplée à une carence en vitamine B1, il faut d'abord restaurer le déficit en thiamine puis seulement perfuser du glucose et non l'inverse. En effet, la thiamine sert de coenzyme au complexe enzymatique pyruvate déshydrogénase, enzyme nécessaire à la conversion du pyruvate en Acétyl CoA dans la voie de métabolisation du glucose.

\section{Anesthésie Générale : définitions, signes, physiopathologie et traitement}

C'est un état de conscience altéré (coma réversible) pharmacologiquement induit, fonctionnellement équivalent à une dépression du tronc.

Condition réversible :

- Inconscience

- $\quad$ Amnésie (oubli)

- Analgésie (pas de douleur)

- Ataxie (pas de mouvement)

Stabilité des systèmes autonomes : cardiovasculaire, respiratoire et thermorégulateur

Patterns EEG spécifiques : activités lentes de haute amplitude (ou voltage) augmentant au fur et à mesure que l'anesthésie est profonde $\rightarrow$ activités EEG des patients comateux

Le propofol induit l'inconscience par inhibition via du GABA A du largage de l'histamine dans le cortex (à partir du noyau tubéromammilaire localisé dans l'hypothalamus)

L'inconscience peut être levée par administration de cholinomimétique comme la physostigmine ce qui est bien la preuve qu'on interfère avec la substance réticulée. C'est bien la preuve que les 2 
neurotransmetteurs qui permettent l'éveil sont l'histamine et l'acétylcholine. L'anesthésie est une forme de coma réversible. 


\section{Epilepsie}

\section{Généralités}

Les convulsions sont des évènements paroxystiques dus à un excès de synergie neuronale anormale dans le cerveau dont les manifestations cliniques peuvent être variables. Les convulsions, de par leur définition, sont des évènements isolées et ne devraient pas se reproduire chez un sujet : elles sont donc à ne pas confondre avec les épilepsies, définis par des convulsions récurrents causées par un processus neurologique sous-jacent. L'épilepsie est un des problèmes neurologiques les plus courant au monde : environ 3\% de la population mondiale présentera de l'épilepsie à un moment donné de son existence. Les crises spécifiques peuvent être différenciées selon leurs caractéristiques cliniques (partielles complexes, tonico-cloniques). Les syndromes épileptiques sont des entités différenciées selon le type de crise, la présence ou absence d'anomalies neurologiques ou développementales et les caractéristiques électroencéphalographiques.

\section{Classification}

Il existe 2 grandes catégories de syndromes épileptiques : les syndromes généralisés et les syndromes partiels.

Les épilepsies généralisées débutent le plus souvent simultanément dans les deux hémisphères cérébraux, des nombreuses formes ont une forte composante génétique et pour la plupart des patients la fonction neurologique est normale. Les épilepsies généralisées peuvent être cloniques (, toniques, tonico-cloniques, absences, myocloniques, ou atoniques.

Les épilepsies partielles ont une origine focale mais peuvent envahir l'ensemble du cerveau; la plupart sont supposées résulter de lésions du SNC mais souvent ces altérations ne sont pas identifiées. Elles peuvent être simples ou complexes. Les manifestations des épilepsies partielles peuvent être motrices ou vocales, sensorielles (hallucinations simples visuelles, somesthésiques, auditives, gustatives, olfactives, vertigineuses), autonomes (pâleur, rougeur, transpiration, chaleur, froid, piloérection, mydriase, tachycardie/bradycardie, nausées, vomissements), cognitives (dysphasie, dysmnésie, illusions ou hallucinations complexes), psycho-affectives (frayeur, rire, larmes). 


\subsection{Crise généralisée tonico-clonique}

La crise tonico-clonique présente des éléments des crises cloniques et des crises toniques. La crise débute sans prodrome, même si parfois certaines personnes en aperçoivent 1 . La contraction tonique survient en premier, il s'agit d'une contraction de tous les muscles du corps. La contraction du larynx et de l'expiration génère le «cri ictal ». La contraction de la mâchoire pourrait mordre la langue. La respiration est irrégulière, tandis que le rythme cardiaque, pression artérielle et diamètre pupillaire augmentent.

Après 10-20s, la phase tonique évolue vers la phase clonique, c'est à dire la superposition des phases de relaxation des muscles. Cette relaxation augmente jusque la fin de la crise. L'incontinence urinaire peut être présente. La confusion post-ictal peut parfois durer des heures. La phase tonique de l'EEG est représente une augmentation progressive d'une activité générale à voltage bas. La phase clonique de l'EEG est représentée par des grandes ondes interrompues par des spike (spike and wave pattern ou pointe-onde).

\subsection{Crise généralisée de type absence}

Les épilepsies absences débutent souvent dans l'enfance, caractérisée par des pertes soudaines de conscience sans perte de contrôle postural. La conscience revient après quelques secondes sans confusion post-ictal. La manifestation clinique, habituellement très pauvre et représentée par une rupture de contact et un regard fixe peut parfois aussi inclure des automatismes moteurs bilatéraux comme cligner des yeux, mouvement de mastication, ou mouvements cloniques de la main à petite amplitude. L'EEG montre un caractéristique pointe-onde de $3 \mathrm{~Hz}$ de quelques secondes de durée superposé à un EEG normal. L'origine des crises se situe dans le thalamus et aussi le cortex.

Il existe des crises absences atypiques ou l'activité EEG est de plus petite amplitude et de morphologie atypique; ces crises sont moins sensibles aux anticonvulsivants et sont le symptômes de défauts neurologiques et retard mental sous-jacents. 
Pour une minorité, la crise d'absence sera accompagnée d'une crise généralisée tonico-clonique. Cette généralisation peut s'expliquer par un des circuits thalamocortical composé de 3 populations neuronales à savoir :

1. Les neurones thalamiques réticulaires ;

2. Les neurones thalamiques relais;

3. Les neurones corticaux pyramidaux ;

En cas de généralisation de la crise, ce circuit va mettre l'ensemble du cerveau dans un état de synchronisation nécessaire à la généralisation de la crise épileptique (pour rappel les cellules d'un foyer épileptique ont 2 caractéristique : hyperexcitabilité et hypersynchronisme). Pour synchroniser le cerveau, les neurones thalamiques réticulaires vont hyperpolariser les neurones thalamiques relais. Quand ces derniers sont hyperpolarisés, ils fonctionnent en mode bouffée et permettent la synchronisation des neurones corticaux pyramidaux; il y a alors généralisation de la crise. Le mode bouffée est permis grâce à des canaux Ca2+ de type $\mathrm{T}$ dont le seuil de dépolarisation est bas. Une fois, le seuil bas de dépolarisation atteint, les canaux $\mathrm{Na}+$ voltage dépendant vont prendre le « relais » et générer beaucoup de potentiels d'action : c'est le mode bouffée.

En sommeil NON REM, les neurones thalamiques relais fonctionnent en mode bouffée ce qui permet de mettre le cerveau dans un état synchrone.

En sommeil REM, les neurones thalamiques relais fonctionnent en mode tonique ce qui ne permet plus la synchronisation et on a le cerveau qui est dans un état désynchronisé.

Dans l'épilepsie d'absence, on a donc une situation similaire au sommeil NON REM, qui produit une activité rythmique du cortex pendant l'éveil (en effet le patient est réveillé quand subit la crise d'absence), ce qui produit les décharges pointes ondes à l'EEG et les manifestations cliniques caractéristiques de l'épilepsie d'absence.

Donc le concept principal est le suivant : il y a une dysfonction d'un circuit neuronale qui produit un état physiologique d'activation rythmique corticale (comme dans le sommeil NON REM) qui peut 
aboutir au déclenchement d'épisodes anormaux d'activités paroxystiques caractérisées par une activation rythmique corticale (crise d'absence).

A l'heure actuelle, des hypothèses existent pour expliquer les crises d'absence comme des anomalies des canaux calcium de type $\mathrm{T}$. Il y aurait aussi probablement une altération des récepteurs GABA favorisant l'excitation par rapport à l'inhibition (PPSE >PPSI). Ces crises disparaissent à la puberté.

Le traitement est l'acide valprö̈que (large spectre d'activité donc fonction aussi pour autres types d'épilepsie) ou l'ethosuximide (spécifique aux crises d'épilepsie d'absence donc ne fonctionne pas pour les autres crises d'épilepsie). Faire attention au baclofen, agoniste des récepteurs GABA qui en général est un bon traitement des crises d'épilepsie mais dans le contexte des crises d'épilepsie d'absence, il favorise l'apparition de crise d'absence accompagnée de crise généralisée tonicoclonique. Pour les mêmes raisons, il faut aussi se méfier des benzodiazépines.

\subsection{Crises généralisées myocloniques}

Un myoclonus est une contraction brève et soudaine du muscle qui peut inclure un seul muscle ou tous les muscles du corps. Un exemple de myoclonus est le mouvement saccadé soudain que l'on fait lorsque on s'endort. Un myoclonus pathologique est le plus souvent observé lors de désordres métaboliques ou des maladies dégénératives du SNC ou encore des dégâts anoxiques cérébraux. L'EEG peut présenter une décharge pointe-onde synchrone mais cette dernière peut être cachée par des artefacts dus au mouvement.

\subsection{Crises généralisées atoniques}

La crise atonique est caractérisée par la perte du tonus musculaire postural pendant 1-2 secondes sans confusion post-ictale (le plus souvent). Au niveau de l'EEG, des pointes ondes soudaines et de brève durée sont observés. Ces crises sont le plus souvent associées à des syndromes épileptiques.

\subsection{Crises généralisées associées à des mutations des gènes des canaux ioniques}

Alors que la plupart des épilepsies généralisées ont une hérédité complexe, quelques-unes ont une hérédité de type simple et sont liées à la mutation d'un seul gène. Dans ces cas les mutations concernent les gènes qui encodent les protéines des canaux ioniques 
- Epilepsie généralisée avec convulsions fébriles : convulsions fébriles associées à des crises d'épilepsies de type absence ou myoclonique ou atonique ou tonico-clonique, de transmission $\mathrm{AD}$ (chromosome 19q), mutation dans le gène du canal sodium voltage dépendant (sous unité $\beta 1$ ) Gène SCN1B - modifie les propriétés d'inactivation du canal

- Convulsions néonatales familiales bénignes : crises d'épilepsies généralisées dans les premiers jours, disparaissent spontanément après quelques mois. Transmission $\mathrm{AD}$, mutations dans les gènes KCNQ2 et KCNQ3 des canaux potassium. La réduction des courants potassiques des canaux mutés est probablement à l'origine de l'hyperexcitabilité constatée. Dans ces syndromes épileptiques des mutations dans des gènes codant pour des protéines des canaux ioniques causent une hyperexcitabilité de neurones corticaux en changeant la fonction des canaux ioniques concernés

\subsection{Epilepsie partielle bénigne à pointes centro-temporales}

Début entre 3 et 14 ans, épilepsie focale fréquente de l'enfant. Il s'agit de myoclonies et paresthésies de la joue sans perte de conscience le jour et de crises d'épilepsie généralisée la nuit. L’EEG intercritique est caractérisé par des pointes centrales et temporales uni ou bilatérales, et dans 30\% des cas aussi de l'activité pointe-onde généralisée. Le pronostic est bon.

\section{Manifestations cliniques selon lobe atteint (crise partielle)}

\section{$\underline{3.1 \text { Crise occipitale }}$}

Une crise occipitale est caractérisée par

1. Hallucinations visuelles

2. Illusions visuelles

3. Hémianopsie/cécité

4. Déviation oculogyre

5. Nystagmus 
6. Flutter palpébral

\section{$\underline{3.2 \text { Crise pariétale }}$}

1. Hallucinations sensitives

2. Illusion somatique

3. Somatognosie

4. Illusions de mouvement

5. Illusions visuelles

6. Dysphasie, dyspraxie, dyslexie, dyscalculie

7. Expérience extracorporelle

\section{$\underline{3.3 \text { Crise frontale }}$}

1. Crise motrice simple clonique ou tonique

2. Oculocéphalogyrie (mouvements de la tête liés à la vision)

3. Postures toniques

4. Crises hypermotrices (hyperactivités ou vocalisations)

5. Absences frontales

\subsection{Epilepsie temporale}

1. Manifestations autonomes

2. Peur, panique

3. Automatismes oraux

4. Posture dystonique (anormale)

5. Automatismes manuels

6. Hallucinations olfactives (cacosmie)

7. Déjà vu

8. Hallucinations auditives

9. Illusions auditives 


\section{Déclenchement d'une crise d'épilepsie}

L'activité synchrone d'un petit nombre de neurones dans un foyer épileptique peut être détectée par l'EEG comme une pointe. Les neurones au sein d'un foyer épileptique sont le siège de dépolarisations paroxystiques synchrones (PDS), signe d'une excitabilité anormale dérivée d'anomalies de l'excitabilité des canaux sodium, potassium et calcium et d'un déséquilibre entre GABA et glutamate. L'excitation est donc bien plus importante que l'inhibition, ce qui sera la cible des traitements pharmacologiques qui augmenteront l'influence GABA (diazepam) ou diminueront l'excitabilité des canaux $\mathrm{Na}+$ voltage dépendants (diphantoine, carbamazépine, lamotrigine).

Le foyer épileptique est la zone où va débuter l'épilepsie. Il est dû à un groupe de neurones anormaux qui ont comme caractéristiques :

Réponse électrique/dépolarisation stéréotypée et synchronisée (= PDS pour paroxysmal dépolarisation shift) :

1. Brusque

2. Ample $(20-4 \mathrm{mV})$

3. Longue durée (50-200ms)

4. Train de potentiels d'action après le PA normal

5. Suivie d'une hyperpolarisation

Déroulement d'une crise classique :

1. Aura (= annonce la crise) : peur, cacosmie (= modification des odeurs), « boule montante » dans la gorge, $\ldots \rightarrow$ cela annonce l'origine de la crise.

2. Augmentation de l'activité du foyer épileptique avec apparition de clonies.

3. Généralisation avec perte de conscience.

4. Extension de la rigidité (phase tonique $- \pm 30 \mathrm{sec}$ ) :
a. Cris (diaphragme, thorax)
b. Perte d'urine
c. Cyanose (tellement contractés qu'ils ne respirent plus) 
d. Fermeture de la mâchoire

5. Clonies généralisées (phase clonique $- \pm 2 \mathrm{~min}$ ).

6. Période post-ictale (somnolence, céphalées) : coma post épileptique

7. Normalement, la crise s'arrête toute seule

\section{$\underline{\text { 5. Sclérose hippocampique }}$}

La sclérose hippocampique correspond à une perte neuronale associée à une gliose (prolifération des cellules gliales) de la région mésiotemporale. Une des causes les plus classiques associées à l'épilepsie temporale est la sclérose hippocampique. Il est important de noter que certaines régions du cerveau sont plus prédisposées que d'autres à présenter un foyer épileptique : c'est le cas du lobe temporal qui est propice au développement d'un foyer épileptique et plus particulièrement au niveau de la région mésiale du lobe temporal en la personne de l'hippocampe (structure intervenant dans la mémoire). Un des facteurs de risque de présenter une sclérose hippocampique, cause principale de crise d'épilepsie temporale, est de faire des convulsions fébriles prolongées durant l'enfance.

Pour mieux comprendre, il faut rappeler les voies hippocampiques. On a tout d'abord la voie perforante qui rentre dans l'hippocampe pour ensuite donner les fibres moussues. Ces fibres moussues vont donner des collatérales pour les cellules granulaires du gyrus dentatus mais leurs destinations finales sont les cellules CA3. Une fois passé par les CA3, les fibres moussues donne une grosse collatérale (= collatérale de Schaffer) à destination des CA1. La sortie de l'hippocampe se fait par le Fornix. Voie perforante $\rightarrow$ fibre moussue $\stackrel{C A 3}{\longrightarrow}$ collatérale de schaffer $\stackrel{C A 1}{\longrightarrow}$ fornix

Pour expliquer la génération de crise d'épilepsie à partir d'une sclérose hippocampique, on peut citer 3 phénomènes qui favorisent l'apparition d'un état hyperexcitable :

1. Réorganisation structurelle (avec création de nouveaux circuits modifiant la balance excitation/inhibition en faveur de l'excitation ;

2. Interneurones excitateurs localisés au niveau du gyrus dentatus qui normalement activent les interneurones inhibiteurs semblent disparaitre de manière sélective. 
3. Neurogénèse: il existe des cellules souches neuronales dans le gyrus dentatus de l'hippocampe qui se divisent.

Ces 3 phénomènes aboutissent à la génération d'une hyperexcitabilité locale.

Le traitement est chirurgical : exérèse du foyer épileptique en faisant attention de ne pas toucher les zones du cerveau qui remplissent des fonctions indispensables afin de garder une qualité de vie égale à auparavant mais sans les crises d'épilepsies. 


\section{Démences et maladie d'Alzheimer}

\section{$\underline{\text { 1. Maladie d'Alzheimer }}$}

Le facteur de risque principal est l'âge. L'incidence double tous les 5 ans à partir de 65 ans. La probabilité de recevoir un diagnostic de maladie d'Alzheimer (AD, Alzheimer's Disease) après 85 ans est supérieur à 1 sur 3 . Le décès survient dans les 3 à 9 ans après le diagnostic.

La $\mathrm{AD}$ est une maladie neurodégénérative appartenant aux démences primaires. Son évolution est progressive sur 8 à 10 ans et le malade présente :

1. Atteinte mnésique (mémoire à court terme)

2. Une désorientation spatio-temporelle

3. Problème de langage

4. Problème de calcul (acalculie)

Ce sera dans un premier temps une atteinte mnésique puis une désorientation spatio-temporelle, le reste arrivant encore après. Cela s'explique par le fait que les dépôts d'amyloïde beta qui explique en partie la maladie se forment d'abord dans la région mésiale des lobes temporaux. Ces régions mésiales (dont l'hippocampe) sont indispensables pour la mémoire.

Le patient peut présenter d'autres signes comme :

1. Passivité (pas intéressé)

2. Agressivité

3. Suspicieux

4. Pauvreté émotionnelle

5. Hallucinations

6. Délire paranoïde

7. Dépression (très souvent) 
Mécanisme :

Il existe peu de formes familiales dans la maladie d'Alzheimer contrairement aux autres maladies neurodégénératives où les formes familiales sont courantes. Ici, dans l'AD, le plus souvent on a à faire à des formes sporadiques.

Cependant ce sont les formes familiales qui nous ont permis de comprendre les mécanismes intervenant dans la maladie.

Les sujets atteints de trisomie 21 développent de manière précoce des démences et on a constaté lors de l'autopsie de leur cerveau qu'il présentait des lésions histologiques à celle d'un patient atteint de l'AD. C'est ainsi qu'on a identifié chez les sujets trisomiques, une anomalie du gène qui code pour l’APP (gène précurseur de la protéine amyloïde).

D'autres entités ont pu être mises en évidence comme la préséniline (pré=avant séniline= sénile $\rightarrow$ vieux) qui est une protéine qui forme un complexe avec le beta et la gamma sécrétase. Le gène qui code pour le préséniline est sur le chromosome 14.

La pathogénie de l'AD dépend donc probablement de l'interaction de plusieurs gènes.

La AD est une amylopathie et NON une tauopathie car il semble que le processus de départ soit une accumulation d'amyloïde beta. Cette accumulation d'amylö̈de beta précède celle des Tau. C'est d'ailleurs l'accumulation d'amyloïde beta qui favoriserait l'accumulation des TAU.

Via les modèles de souris on a découvert la nécessité d'une combinaison d'amyloïde et de la protéine tau pour aboutir à un processus qui entraîne une démence.

Les anomalies principales rencontrées dans AD sont:

1. Anomalies protéiques (amyloïde beta et tau)

2. Altération des fonctions des synapses à cause de amyloïde beta qui est toxique

3. Anomalies mitochondriales (amyloïde beta est toxique pour les mitochondries, qui se rompent : il y a une libération de caspases ou cytochrome qui induit l'apoptose)

4. Stress oxydatif 
5. Effet vasculaire (angiopathie amyloïde dans $90 \%$ des AD donc souvent la démence est mixte (primaire et secondaire (vasculaire))

6. Inflammation (processus inflammatoire au niveau des plaques qui perturbent le fonctionnement des neurones)

7. Calcium (pores à calcium grâce à amyloïde beta qui entraîne l'apoptose)

8. Déficit de transport axonal (surtout à cause de tau)

9. Anomalie du métabolisme du cholestérol (souvent associé à hyper cholestérolémie : apoE)

Donc les amyloïde beta vont se déposer au cours du temps. C'est un processus qui est lié à la sénescence. En fonction de la chance que l'on a, on va avoir des protéasomes suffisamment performants pour détruire les plaques ou alors la chance de ne pas trop produire de amyloïde beta.

Traitement :

Pour expliquer le traitement actuel de la maladie d'Alzheimer, il est important de comprendre l'hypothèse cholinergique. Chez les patients atteints de la maladie d'Alzheimer, on a remarqué un parallélisme entre la perte des neurones cholinergiques et le degré de démence. En effet au cours du temps, on s'est rendu compte de l'importance du noyau basal de Meynert qui contient des neurones à acétylcholine. Ce noyau à acétylcholine projette sur le cortex cérébral. L'utilisation de physostigmine (inhibiteur cholinestérase) associée à la lécithine (précurseur de l'ACh) a permis d'améliorer de manière transitoire les fonctions mnésiques des patients atteints de la maladie d'Alzheimer dans un stade précoce de la maladie. En effet après un certain temps, ce type de traitement n'a plus d'effet car le neurone sont de + en + détruits ce qui ne permet plus un largage endogène d'acétylcholine. Ce médicament a été remplacé à cause de sa forte toxicité hépatique et a été remplacé par d'autres inhibiteurs de cholinestérase (aricept, exelon, reminyl). Ces derniers ont aussi des effets secondaires comme des nausées et des vomissements. Il est important de noter que dans le cadre de nombreuses 
pathologies, le médecin est amené à prescrire des anticholinergiques. Si le patient est jeune aucun problème est relevé mais si le patient est âgé, attention avant de prescrire un anticholinergique car si patient MCI (mild cognitive impairment), le traitement anticholinergique pourrait causer une démence. Une chose intéressante à observer dans ce cas sont les biomarqueurs dans la ponction lombaire : si les résultats montrent un dépôt d'amylö̈de beta 42 (la forme la moins soluble) bas et une tau hyper phosphorylée haute, la prescription d'anticholinergiques empirerait la situation du patient. A l'heure actuelle, des études sont en cours pour des traitements prometteurs comme la vaccination avec amyloïde beta qui semble prometteuse. Le principe est le suivant : on veut induire une réaction immunitaire qui va détruire l'amyloïde beta au lieu du protéasome. A un stade avancé de la maladie, ce traitement est relativement risqué puisqu'on a observé des cas d'encéphalite. Les études de ce traitement se portent donc aujourd'hui sur des patients à un stade précoce de la maladie où on espère avoir une réaction inflammatoire d'une plus petite ampleur. Un autre traitement prometteur serait d'injecter des immunoglobulines intraveineuses (comme on le fait dans le cadre de la myasthénie), pour que les Ig se fixe à l'amyloïde beta spécifiquement pour ainsi favoriser son élimination via le système du complément par exemple.

2 Biochimie pathologique et physiopathologie de la protéine amyloïde beta et de la protéine tau Dans nos neurones, nous synthétisons tous une APP (protéine précurseur de l'amyloïde) qui se trouve dans la membrane cytoplasmique des neurones. Dans le processus normal, l'APP est clivée via l'alpha sécrétase dans un premier temps pour donner sAPPalpha et c83 qui reste dans la membrane. Dans un second temps, c83 est clivée par l'enzyme gamma sécrétase qui donne p3 et AICD (fragment amyloïde intracellulaire qui sert de facteur de transcription). Dans le processus pathologique, l'APP n'est plus clivée par l'alpha sécrétase mais par la beta sécrétase ce qui va aboutir à sAPPbeta et c99. Ensuite la gamma sécrétase clive c99 pour donner l'amyloïde beta et AICD (fragment amyloïde intracellulaire qui sert de facteur de transcription).

L'amyloïde beta a tendance à s'agréger et à former des plaques d'amyloïdes en intracellulaire mais aussi en extracellulaire. L'amyloïde beta outre le fait de s'agréger en plaques peut aussi former des 
pores au niveau des neurones, faisant ainsi entrer du calcium dans le neurone induisant in fine la mort du neurone par apoptose.

Il existe différentes formes d'amyloïde beta. L'amyloïde beta 40 est la forme la plus soluble alors que l'amyloïde beta 42 est la forme qui a la plus grande tendance à s'agréger. Il semblerait que l'agrégation intracellulaire des amyloïde beta soit un moindre mal (principe des déchets nucléaires) alors que les amyloïde beta solubles seraient les plus toxiques pour le cerveau. Donc amyloïde beta 40 qui est la forme la plus soluble serait la forme d'amyloïde beta la plus dangereuse.

Comme l'APP, tout le monde produit des protéines Tau. En effet, la protéine Tau est indispensable pour le fonctionnement normale des neurones dans la mesure où elle fait partie de la famille des protéines associées aux microtubules (on parle de $\mathrm{MAP}=$ microtubule associated protein). Les microtubules sont indispensables pour le transport axonal. La protéine tau ne sait remplir sa fonction que lorsqu'elle est peu phosphorylée. Si la protéine tau devient hyper phosphorylée, elle se dissocie des microtubules et a tendance à s'agréger pour former des dépôts neurofibrillaires. Comme pour l'amylö̈de Beta, les neurofilaments solubles sont les plus embêtants et les neurofilaments insolubles formant un agrégat à l'intérieur du neurone semble être un moindre mal (principe des déchets nucléaires). 


\section{Démence à corps de Lewy (DLB)}

Les corps de Lewy sont des agrégats anormaux de protéines (alpha-synucléine) qui se forment à l'intérieur des cellules nerveuses dans la DLB et la maladie de Parkinson. Ce sont des inclusions cytoplasmiques éosinophiles composées de fibrilles d'alpha-synucléine.

LA DLB fait partie des alpha-synucléinopathies comme la maladie de Parkinson. Les corps de Lewy dans la maladie de Parkinson se déposent dans la substance noire alors que dans la DLB, ils se déposent sur un ensemble de structures corticales notamment les lobes occipitaux. La DLB représente 15 à $20 \%$ des démences comme les démences vasculaires en termes de fréquence.

Il y a 2 types de critères pour diagnostiquer une DLB :

- Des critères centraux :

1. Démence fluctuante

2. Hallucinations visuelles récurrentes

3. Parkinsonisme (anomalie du mouvement)

- Des critères suggestifs :

1. REM sleep behaviour disorder (le patient vit son rêve) ;

2. Sensibilité excessive aux neuroleptiques ( $=$ antipsychotique) qui sont des médicaments qui bloquent la transmission dopaminergique;

3. Anomalies dopaminergiques dans les ganglions de la base (IRM fonctionnelle : moins bonne captation du fluorodopa chez patient DLB que chez normal)

Si deux critères sont présents dont un critère central, le diagnostic est probable.

Si 1 seul critère est présent, le diagnostic est possible. 


\section{Démence fronto-temporale (DFT)}

La DFT est le prototype des tauopathies. La DFT représente 15 à $20 \%$ des démences. Comme le nom l'indique, ce sont des sujets qui vont avoir une atrophie particulièrement marquée au niveau frontal et temporal. Contrairement à $\mathrm{AD}$, la DFT est dans 30 à $50 \%$ des cas une forme familiale alors que pour $\mathrm{AD}$, c'était moins de $1 \%$ de formes familiales.

La deuxième grande différence avec $\mathrm{AD}$ est que dans la $\mathrm{DFT}$, il y a conservation de la mémoire en tout cas au début de la maladie.

Donc si on devait résumer les différences entre $\mathrm{DFT}$ et $\mathrm{AD}$, on a :

1. Préservation de la mémoire pour DFT ;

2. Formes familiales quasi $50 \%$ (retenir le chiffre de 1 sur 2 );

Les critères pour le diagnostic de la DFT sont le présentation de 3 syndromes :

1. Syndrome comportemental (lobe frontal);

2. Syndrome langagier (lobe temporal) :

- Aphasie progressive non fluente

- Démence sémantique

3. Syndrome moteur :

- Dégénérescence corticobasale qui donne une dystonie (mouvements anormaux) et une apraxie

- Paralysie supra-nucléaire progressive (aussi une tauopathie)

Ces 3 syndromes peuvent survenir avec ou sans parkinsonisme et avec ou sans maladie du motoneurone (cf SLA). La classification de Cambridge classe les DFT en 2 formes :

1. Forme comportementale ;

2. Forme langagière :

La forme comportementale va aboutir à des changements progressifs insidieux de la personnalité et du comportement. 
Les manifestations cliniques de la forme (variante) comportementale sont :

1. Perte d'introspection (la personne va entrer dans des délires) ;

2. Indifférence ;

3. Désinhibé, impulsif (au point de prendre son arme et tirer), comportement asocial ;

4. Distraction, irritable, agressif, réactions violentes ;

5. Comportements inappropriés (surtout par commentaire et geste);

6. Euphorie, estime de soi exagérée ;

7. Apathie, mutisme ;

8. Modifications des habitudes alimentaires (hyperphagie : la personne se précipite sur le buffet)

La forme langagière va aboutir à des changements progressifs insidieux du langage.

Les manifestations cliniques de la forme (variante) langagière sont :

1. Aphasie non fluente progressive (B);

2. Démence sémantique $(W)$;

3. Prosopagnosie (ne reconnait plus les visages);

Le diagnostic est quadridimensionnel :

1. Clinique ;

2. Topographie (imagerie) ;

3. Neuropathologie (biomarqueurs, autopsie);

4. Génétique (1 cas sur 2$)$

Donc $20 \%$ des maladies neurodégénératives sont de type DFT. Les formes comportementales, c'est 3/4 des cas et les formes langagières $c^{\prime}$ est $1 / 4$ des cas.

Ce qu'on va avoir en neuropathologie, c'est un dépôt de protéines tau dans 50\% des cas (rappel: DFT = tauopathie) et un dépôt de protéines TDP-43 avec de l'ubiquitine dans aussi environ $50 \%$ des cas. Ce problème d'accumulation de protéine se rencontre aussi bien dans les formes sporadiques que 
dans les formes familiales. Donc encore une fois, le dépôt protéine tau est un élément clé pour le développement de la maladie.

Dans les variantes de tauopathies, on a parlé de la DFT comportementale et langagière. On a une autre entité dans les tauopathies qui est la paralysie supranucléaire progressive.

\section{Paralysie supranucléaire progressive (PSP)}

En général, une «paralysie» est une faiblesse motrice ou d'une partie du corps. Le terme «supranucléaire » se réfère à la nature du problème oculaire dans la PSP. Bien que certains patients atteints de PSP décrivent leur symptôme comme "flou», le problème réel est l'incapacité d'une visée correcte des yeux à cause d'une faiblesse (ou paralysie) des muscles qui mettent en mouvement les globes oculaires. Ces muscles sont contrôlés par des cellules nerveuses qui résident en grappes, ou "noyaux», près de la base du cerveau, dans le tronc cérébral. La plupart des problèmes qui affectent les mouvements oculaires ont pour origine ces noyaux du cerveau, mais dans la PSP le problème provient des parties du cerveau qui contrôlent ces noyaux euxmêmes. Ces zones de contrôle «plus élevées» sont ce que le préfixe «supra» désigne dans « supranucléaire » (au-dessus des noyaux).

Les critères diagnostiques sont :

- Tous les suivants :

1. Début après 40 ans ;

2. Evolution progressive ;

3. Bradykinésie ;

4. Paralysie des mouvements oculaires (d'où le nom de la maladie) ;

- + trois des suivants :

1. Dysarthrie, dysphagie ;

2. Rigidité axiale > membres (hypertonie avec nuque en extension) ; 
3. Tremblement minimal ou absent ;

4. Chutes fréquentes (troubles de la marche);

5. Signes pyramidaux ;

Ce sont des sujets qui seront incapables de porter volontairement le regard vers le bas : c'est vraiment une des caractéristiques de la maladie. C'est bien entendu lié au fait que les premières structures qui sont touchées dans ces maladies neurodégénératives concernent la structure du cerveau où il y a la commande oculaire.

Le décès a lieu dans les 9 ans qui suivent le diagnostic.

Lorsqu'on a aussi une atteinte bulbaire, on a tendance à mourir + vite car toutes les commandes motrices qui se trouvent au niveau bulbaire sont essentielles à la survie.

La caractéristique principale de cette maladie est aussi l'atrophie mésencéphalique. Au niveau radiologique, on a le signe du pingouin ou du colibri car l'atrophie mésencéphalique donne au tronc cérébral la forme du bec d'un oiseau.

Donc dans la paralysie supranucléaire progressive, le tronc cérébral va subir une atrophie mésencéphalique et en + de cela, il peut éventuellement y avoir une atteinte bulbaire réduisant ainsi l'espérance de vie.

\section{Maladies à prions}

Les maladies à prions ou maladie de Creutzfeldt-Jakob (CJD) sont des maladies rares mais catastrophiques. On rencontre 3 formes de maladies à prions :

1. Génétiques $(15 \%)$;

2. Sporadiques ( $85 \%$ : mutation lors de la gamétogénèse : les 2 parents sont sains) ;

3. Acquises (1\%) ;

A partir du moment où la maladie se déclare, dans $90 \%$ des cas le décès a lieu dans l'année (pronostic catastrophique). L'âge moyen de développement de la maladie est de 61 ans. 
LA CJD n'est pas une maladie infectieuse transmise de façon habituelle. Il n'y a aucun danger à soigner une personne atteinte de la CJD (car transmise par inoculation ou contact alimentaire). Le prion est comparé à un virus lent en raison de sa longue période d'incubation (de 12 mois à 30 ans) avant que les signes ne se manifestent.

Une maladie à prion est une maladie infectieuse à protéine mutée et non due à un virus ou une bactérie. Les prions (protéines mutées) se multiplient en recrutant leur équivalent cellulaire normal et en induisant leur conversion en formes infectantes ce qui explique l'aspect infectieux et le fait que ça se propage au cerveau. Donc ici, l'agent pathogène ne contient ni ADN ni ARN. C'est une protéine qui peut-être protéolysée et qui dans ce contexte-là peut se polymériser, se déposer et produire de l'amyloïde entre autre.

Un des mécanismes qui explique la toxicité des prions, c'est un blocage de la fonction du protéasome notamment. Si ces agrégats de prions bloque le protéasome, ça va d'autant + favoriser l'accumulation des protéines anormales dans le cerveau qui va aboutir à l'aspect spongiforme du cerveau (dans une CJD, le cerveau devient une véritable éponge).

La personne va présenter une démence progressive rapidement évolutive avec :

1. Myoclonies ;

2. Syndromes pyramidal ou extrapyramidal ;

3. Troubles visuels ou cérébelleux ;

4. Mutisme akinétique;

Au niveau du LCR, il y aura une protéorachie un peu élevée et au niveau de la RMN, on verra des anomalies des structures corticales et des noyaux de la base.

Exemples: encéphalopathie spongiforme bovine (maladie de la vache folle)/ L'insomnie fatale familiale est une encéphalopathie d'origine exclusivement génétique (forme sporadique). L'IFF débute généralement vers 50 ans et se caractérise par des troubles du sommeil paradoxal qui évoluent vers 
une insomnie rebelle associée à des troubles neurovégétatifs. Progressivement, des troubles des mouvements et la démence apparaissent. L'issue de la maladie est fatale après 6 à 30 mois d'évolution.

\section{$\underline{\text { 7. Démences secondaires dues à une carence en Vitamine B12 }}$}

Une carence en vit B12 peut être due à :

1. Alimentation végétarienne mal équilibrée ;

2. Ethyliques qui n'ont pas besoin de manger ;

3. Utilisation d'inhibiteur de la pompe à proton (on inhibe les cellules pariétales qui libère HCL mais aussi le facteur intrinsèque indispensable à l'absorption de la vitamine B12 au niveau iléale) ;

4. Anémie de Biermer (maladie auto-immune) ;

5. Chirurgie bariatrique ;

6. Insuffisances pancréatiques ;

7. Pathologie iléale : maladie de Crohn ou tuberculose intestinale

La vitamine B12 joue le rôle de cofacteur dans 2 réactions chimiques :

$$
\text { Homocystéine } \stackrel{\text { Vit B12-Vit B9 (acide folique) }}{\longrightarrow} \text { méthionine }
$$

$$
\text { Ac. méthylmalonique } \stackrel{\text { vit B12 }}{\longrightarrow} \text { succinyl }- \text { CoA }
$$

Si présence d'une carence en vitamine B12, on observera une accumulation d'homocystéine et d'acide méthyl malonique.

Le dosage de vitamine B12 démontre son éventuelle carence. Si $>400$ pg/ml, pas de carence, si $<200$ $\mathrm{pg} / \mathrm{ml}$, il y a carence et il faut suppléer. Si entre 200 et 400, on est dans une zone grise où les indications thérapeutiques ne sont pas claires. Donc une chose intéressante à faire est de doser l'homocystéine et l'acide méthyl malonique. Si ceux-ci sont élevés, la carence en vit B12 est objectivée et un traitement de supplémentation sera prescrit. 
Un patient carencé en vit b12 va présenter :

1. Une anémie macrocytaire ;

2. Une atrophie des muqueuses ;

3. Une sclérose combinée au niveau de la moelle épinière (qui se voit très bien en radiologie).

La sclérose combinée est une atrophie des cordons postérieurs (où remonte la voie lemniscale de la sensibilité) et une atrophie des cordons latéraux (où descend le faisceau pyramidal latéral).

Les signes cliniques associés à l'atrophie du cordon postérieur seront une perte de la sensibilité vibratoire au diapason (il ne perçoit plus le diapason au niveau du pied) et une perte du sens de position (donc si debout les yeux fermés, il tombe).

Le signe clinique associé à l'atrophie du cordon latéral sera la présence d'un syndrome pyramidal avec un réflexe cutané plantaire en extension (signe de Babinski).

Bien entendu, la carence en vit B12 ne donne pas qu'une anomalie de la moelle épinière avec la sclérose combinée. On a aussi une atteinte cérébrale qui explique la démence.

\section{Syndrome de Korsakoff}

Le syndrome de Korsakoff est un ensemble de symptômes que peut présenter un patient alcoolique chronique. L'atteinte principale est une atteinte de la mémoire qui est beaucoup plus marquée que les atteintes des autres fonctions cognitives dans ce type de syndrome.

Il y a donc une atteinte temporale et du diencéphale qui vont aboutir à :

1. Mémoire des faits nouveaux et anciens altérés (amnésie importante);

2. Désorientation spatiotemporelle ;

3. Confabulation

Souvent le patient combine un syndrome de Wernicke (encéphalopathie) et un syndrome de Korsakoff. Ce que l'on observe en plus dans le syndrome de Korsakoff est une atteinte du noyau dorsomédial du thalamus. 


\section{Pellagre}

Le pellagre est la maladie des $3 \mathrm{D}$ :

1. Atteinte cutanée (photosensibilité des zones exposées au soleil) : dermatite ;

2. Atteinte digestive : diarrhée ;

3. Troubles cognitifs : démence (dans des cas de carence ++) ;

Le pellagre est du à une carence en tryptophane et vitamine B3. Cela se rencontre dans des populations pauvres dont le régime alimentaire est riche en maïs (ça dépend aussi de la manière dont ce maïs est cuisiné). Cette maladie est devenue rare dans les pays industrialisés mais existe encore dans les pays du tiers monde. 


\section{Sclérose Latérale Amyotrophique}

Remarque préalable sur la terminologie :

- Si atteinte du MN supérieur (cortical) : sclérose latérale primaire (donnant un syndrome pyramidal classique avec hyperréflexie et faiblesse);

- Si atteinte du MN inférieur (spinal) : amyotrophie spinale progressive (donnant une aréflexie, une fonte musculaire et des fasciculations);

- Si atteinte du MN supérieur et inférieur : sclérose latérale amyotrophique ;

\section{Généralités}

Il est important de remarquer qu'il existe un overlap (=recouvrement) entre la démence frontotemporale (DFT) et la SLA. Ca veut dire que certains patients atteints de DFT (30\%) vont développer une SLA.

En Europe, la SLA est aussi appelée maladie de Charcot ;

En Amérique, la SLA est aussi appelée maladie de Lou Gehrig (joueur de baseball) ;

En anglais, on parle de ALS (amyotrophic lateral sclerosis) ou de manière plus générale de MND (motor neuron disease).

La SLA est une maladie neurodégénérative avec une atteinte progressive des neurones moteurs qui commandent les muscles volontaires. La mort survient généralement maximum 3 à 4 ans après le diagnostic de la maladie.

L'incidence semble en augmentation dans les pays industrialisés ce qui laisse présager que certains facteurs environnementaux ont une influence dans le développement de la maladie. L'incidence est de 4/100.000 dans le monde, ce qui est déjà important. L'incidence de la SLA est la même que la sclérose en plaques et 5 fois plus élevée que la chorée de Huntington.

Tous les muscles du corps peuvent être touchés par la maladie: bras, jambe, parole, déglutition et respiration. Une seule exception à savoir les muscles responsables du mouvement des yeux qui sont épargnés. Une perte de motricité se présente lorsque la connexion entre le cerveau et les muscles via 
les motoneurones ne se fait plus. Dans un $2^{\text {ème }}$ temps, on observe une perte de force et une atrophie musculaire.

Donc, généralement, les patients vont développer une paralysie d'un membre (MS> MI et souvent distalement) qui va s'étendre progressivement à l'ensemble des autres motoneurones et muscles. Au fur et à mesure de la maladie, des gestes aussi simples que parler, marcher, avaler deviennent impossibles. Petit à petit, la personne atteinte devient alors lourdement handicapée. Il y a une aggravation en nappes de la maladie, c'est-à-dire que là où les $\mathrm{MN}$ ont été détruits, ce sont les neurones adjacents à cette zone qui vont ensuite être détruit et ainsi de suite.

Dans la forme bulbaire qui constitue la forme la plus grave de la SLA, les premiers neurones touchés sont ceux du tronc cérébral, provoquant rapidement des troubles de la parole, de la déglutition et de la respiration. La forme bulbaire se caractérise par une évolution rapide de la maladie.

La survenue de la SLA est donc le résultat d'une interaction complexe entre 3 facteurs :

1. Vieillissement,

2. Susceptibilité génétique ;

3. Facteurs environnementaux.

\section{Physiopathologie}

4 facteurs jouent un rôle important dans la maladie :

1. Stress oxydatif ;

2. Acides aminés excitateurs ;

3. Calcium libre intracellulaire ;

4. Apoptose. 
1. Stress oxydatif et génétique :

Les SLA familiales ont permis de mieux comprendre la physiopathologie de la maladie. Ces SLA familiales représentent 10\% des SLA (donc bien retenir que pour les formes familiales, la DFT c'était 30 à $50 \%$ alors que la SLA c'est 10\%).

En effet, $20 \%$ parmi les $10 \%$ de formes familiales présentent une mutation du gène qui code pour la SOD (superoxyde dismutase sur le chromosome 21). Cette SOD permet de neutraliser les radicaux libres d'oxygènes qui en trop grand nombre pourraient causer des dommages aux MN.

D’autres mutations pouvant déclencher la SLA ont été découverte entre temps comme la mutation C9ORF72 qui est la plus fréquente puisqu'elle représente plus de $60 \%$ des formes familiales de SLA (donc environ 6\% des SLA). Quand des patients présentent cette mutation, dans 1 cas sur 2, il y aura une démence fronto-temporale associée.

A l'heure actuelle, on ne connait pas encore la fonction du gène C9ORF72. On sait juste que la mutation consiste en une expansion d'hexanucléotides GGGGCC. Le gène devient mutant quand l'expansion est > à 100. Lors de la transcription du gène mutant, on obtient un ARN mutant qui s'agrège dans le noyau et est toxique pour le motoneurone. On a remarqué qu'en Finlande, la fréquence de cette mutation est très importante.

2. Acides aminés excitateurs et facteur environnementaux :

On a remarqué que dans certaines îles du Pacifiques, la fréquence de SLA était 100 fois plus fréquente. On s'est alors rendu compte que c'était du aux habitudes alimentaires de la population locale. Ces populations avaient pour habitude de manger des chauves souris. Le problème, ce n'est pas les chauves souris mais ce que les chauves-souris mangent à savoir des fruits d'un arbre particulier. Ces fruits contiennent un acide aminé excitateur qui est le beta-méthylamino L alanine. Mais on s'est vite rendu compte grâce à des modèles de primates que l'atteinte était aigue et réversible ce qui n'est 
malheureusement pas le cas de la SLA. Cet AA excitateur n'est donc pas suffisant pour induire la SLA. Il faut une $2^{\text {ème }}$ molécule présente dans ce fruit pour expliquer la SLA. Cette molécule est un carcinogène appelé glycoside cycasine.

Donc il faut la combinaison de ces 2 molécules pour expliquer la survenue de la SLA.

Le processus de réparation de l'ADN est quelque chose qui dysfonctionne dans les cancers mais ce processus de réparation fonctionne moins bien aussi avec le vieillissement. C'est ce qui explique pourquoi un des facteurs de risque pour la survenue de la SLA est l'âge.

On sait aujourd'hui que l'excitotoxicité induite par le glutamate est un élément essentiel dans la mort neuronale. Ceci a donc aboutit au développement de molécules qui permettent de diminuer l'excitotoxicité et de produire le seul médicament qui soit un peu efficace à l'heure actuelle: le riluzole.

3. Calcium intracellulaire

On parle des $\mathrm{MN}$, mais aussi les astrocytes (cellules de soutien) qui permettent la recapture du glutamate au niveau des synapses via des transporteurs au glutamate. Dans la SLA, il y a diminution de transporteur au glutamate, ce qui fait que le glutamate reste plus longtemps dans la synapse. On peut alors avoir une entrée de calcium dans les cellules et avoir une atteinte mitochondriale qui peut expliquer aussi les problèmes rencontrés dans la SLA.

\section{$\underline{3 \text { Traitement }}$}

Le rilutek (ou riluzol) est un antagoniste du glutamate (on a vu que le glutamate intervenait dans la mort des neurones) et n'est administré qu'à un stade précoce de la maladie et permet de prolonger la vie du patient de quelques mois. En Belgique, le remboursement nécessite une CV>60\% (atteinte 
respiratoire doit rester limitée). Ces médicaments donnent des effets secondaires comme des nausées, des maux de tête et une hépatotoxicité.

On peut également être amené à administrer des traitements annexes qui visent à améliorer le confort du patient :

1. Pose d'une sonde de gastrotomie (à travers la paroi abdominale, la sonde va directement dans l'estomac pour éviter une dénutrition trop rapide): attention faire attention de ne pas décompenser la patient au niveau respiratoire (car le passage inévitable d'air du tube digestif dans l'abdomen va compliquer le travail du diaphragme pendant la respiration).

2. Ventilation assistée non invasive (juste une pression positive) ;

3. Ventilation invasive (trachéotomie + respirateur) si le patient accepte ;

4. Traitement de la sialorrhée par administration d'anticholinergique ou injection de toxine botulique directement dans les glandes salivaire ce qui altère la transmission para synaptique ;

5. Euthanasie possible si le patient le demande ;

\section{Maladie de Kennedy}

Forme d'amyotrophie spinale progressive (SMA) donc qui touche le MN inférieur. Mais dans la maladie de Kennedy, on n'a pas seulement une atteinte motrice pure. A cette atteinte motrice est associée une atteinte bulbaire (donnant une dysphagie et une dysarthrie), une atteinte sensitive et une gynécomastie ainsi qu'une diminution de la fertilité.

La maladie de Kennedy est liée à $\mathrm{l}^{\prime} \mathrm{X}$ et se transmet selon le mode récessif. Cette maladie va donc toucher essentiellement les hommes de plus de 30 ans. Néanmoins, des femmes porteuses de la mutation, peuvent présenter une atteinte bulbaire discrète.

On a pu mettre en évidence une expansion CAG (si $>40$ devient pathologique) pour un gène du chromosome $\mathrm{X}$ qui code pour le récepteur à androgène. 
L'altération de l'affinité du récepteur à androgène explique la gynécomastie ainsi que la diminution de la fertilité.

L'expansion CAG entraîne un gain de fonction toxique via 4 phénomènes :

1. Agrégation de protéines polyglutamine (qui contiennent beaucoup de glutamine) ;

2. Inclusion neuronale à ubiquitine ;

3. Interférence avec activité du protéasome ;

4. Interférence avec transport cellulaire ;

Ces 4 éléments expliquent la mort des MN inférieur.

Les signes et les symptômes de la maladie de K sont :

1. Crampes, fasciculations, faiblesse des ceintures ;

2. Atrophie musculaire et perte de réflexe (car atteinte du MN inférieur)

3. Dysarthrie, dysphagie, fasciculations faciales et péri-orales (m. masséter) (car atteinte bulbaire);

4. Atteinte sensitive discrète ;

5. Gynécomastie, infertilité, atrophie testiculaire ;

6. Diabète (développe plus fréquemment un diabète) ;

Comme les maladies génétiques où il y a une expansion d'un triplet :

- Une relation inverse entre l'âge d'apparition et le nombre de répétition des CAG : plus on a de répétitions, plus on développe la maladie de manière précoce ;

- Il y a un phénomène d'anticipation génétique (la maladie se présente de + en + tôt et est de + en + grave au fil des générations)

Le pronostic est lié à la sévérité de l'atteinte bulbaire qui inévitablement entraînera des problèmes respiratoires. 


\section{Maladie de Parkinson et anomalies du mouvement}

\section{$\underline{1 \text { Maladie de Parkinson }}$}

La maladie de Parkinson est la deuxième pathologie dégénérative la plus fréquente après l'AD. L'incidence est de 13,4/100.000/an. Elle touche 2 hommes pour 1 femme. L'âge moyen d'apparition de la maladie est de 55 ans.

La maladie de Parkinson est une maladie neurodégénérative qui se manifeste principalement par des troubles du mouvement. Elle peut débuter précocement avant l'âge de 45 ans. En général, la maladie de Parkinson n'est pas mortelle mais évolue peu à peu pour affecter plusieurs aspects de la vie de la personne atteinte.

La maladie de Parkinson s'explique par la destruction de neurones riches en dopamine au niveau de la substance noire compacta (qui fait partie des ganglions de la base : cf. ci-dessous). Au moment du diagnostic de la maladie de Parkinson, environs 70\% des neurones de la substance noire compacta ont déjà été perdu. Cela veut dire que le corps a pu compenser pendant un moment mais lorsque les premiers symptômes apparaissent, le corps n'arrive plus à compenser et il y a décompensation. Cette perte neuronale (perte de neurones à dopamine de la SNc) est généralement associée à l'apparition de corps de Lewy au niveau de la substance noire.

Donc pour résumé dans une maladie de Parkinson, il y a 2 phénomènes qui se produisent au niveau de la substance noire compacta :

1. Une perte des neurones à dopamine ;

2. Formation de corps de Lewy au niveau de la substance noire.

La maladie de Parkinson, du fait de la formation de corps de Lewy est classée dans les alphasynucléinopathies au même titre que la démence à corps de Lewy. Remarquons néanmoins que dans 
certaines maladies de Parkinson familiales comme celle liée à la mutation de la parkine, il n’y a pas formation de corps de Lewy. Donc retenons qu'il y a souvent apparition de corps de Lewy dans la maladie de Parkinson mais que dans certaines formes familiales font exception à cette « règle». La formation de corps de Lewy n'est donc pas indispensable à la survenue d'une maladie de Parkinson.

Mécanisme (physiopathologie) :

Pour comprendre les mécanismes de la maladie de Parkinson, il faut présenter les différents acteurs qui interviennent à savoir les ganglions de la base qui sont :

1. Striatum (putamen, noyau caudé et noyau accumbens) ;

2. Noyau sous-thalamique ;

3. Substance noire (pars compacta qui est touchée dans la maladie de Parkinson et pars reticulata) ;

4. Globus pallidus (interne et externe)

Il existe 3 voies qui permettent au niveau des ganglions de la base qui permettent un mouvement correct :

1. Voie directe qui favorise le mouvement:

- Le cortex moteur (par le glutamate) et la substance noire pars compacta (par la dopamine) viennent exciter le striatum (via les récepteurs à dopamine D1).

- Le striatum envoie alors un influx inhibiteur (GABA et substance P) sur le globus pallidus interne et la substance noire pars reticulata (forment le point de sortie des ganglions de la base).

- Or, le globus pallidus interne et la substance noire envoient des influx inhibiteurs (GABA) vers le thalamus ventro-latéral et les noyaux pédonculo-pontins (voie motrice). 
En activant la voie directe, on favorise/facilite le mouvement.

2. Voie indirecte qui inhibe le mouvement:

- Le cortex moteur (par le glutamate) et la substance noire pars compacta (par la dopamine) viennent activer le striatum (via les récepteurs à dopamine D2).

- Le striatum (par le GABA et l'enképhaline) inhibe le globus pallidus externe.

- Le globus pallidus externe (par le GABA) inhibe le noyau sous-thalamique.

- Le noyau sous-thalamique (par le glutamate) stimule le globus pallidus interne et la substance noire pars reticulata, qui inhibent (par le GABA) le thalamus ventro- latéral et la voie motrice, et qui fait un feedback excitateur sur le globus pallidus externe (par le glutamate).

En activant la voie indirecte, on inhibe le mouvement.

3. Voie hyperdirecte qui inhibe le mouvement :

- Le cortex moteur (par le glutamate) excite le noyau sous-thalamique.

- Le noyau sous-thalamique (par le glutamate) excite le globus pallidus interne et la substance noire.

- Le GPI et la substance noire (par le GABA) inhibent le thalamus ventro-latéral et la voie motrice.

La voie hyperdirecte diminue l'activité motrice, elle inhibe le mouvement.

Les mécanismes de mort neuronale sont les mêmes que dans la plupart des autres maladies neurodégénératives et sont les suivants :

1. Dysfonction de la voie ubiquitine-protéasome ;

2. Anomalies de la conformation des protéines ;

3. Dysfonction mitochondriale ;

4. Stress oxydatif;

5. Inflammation; 
6. Lésions des neurones dopaminergiques qui est plus spécifique à la maladie de Parkinson.

Clinique :

Les principaux signes de la maladie de Parkinson sont:

1. Tremblement de repos (c'est la première chose qui apparait) ;

2. Rigidité (on parle d'hypertonie : résistance accrue à l'étirement passif) ;

3. Akinésie (déficit dans l'initiation du mouvement) ;

4. Bradykinésie (ralentissement des mouvements) ;

5. Instabilité posturale ;

De plus, on va aussi observer d'autres signes mineurs qui ne sont que la conséquence des 5 signes principaux ci-dessus:

1. Perte du ballant du bras d'un côté ;

2. Freezing (geler sur place car demi-tour difficile) ;

3. Micrographie (écrit de moins en moins bien) ;

4. Légèrement vouter (la tête penchée vers le bas)

Traitement :

Ici pas de traitement curatif ni de traitement préventif, on traite juste les symptômes.

Avant, on donnait du L-Dopa tout seul mais cela donnait des effets secondaires majeurs (nausées, vomissements, hypotension orthostatique). Donc aujourd'hui on donne la L-Dopa avec l'inhibiteur de 
la décarboxylase (qui est l'enzyme qui explique les effets secondaires donc il faut l'inhiber). L'ensemble donne ce que l'on appelle le Prolopa.

Au début du traitement, le prolopa va donner une récupération importante. Mais au fur et à mesure, le prolopa agit moins car les neurones continuent à disparaître. A un moment, on va arriver à un stade de la maladie qu'on qualifie de on-off (ou go-non go). A ce moment-là, le patient est dyskinétique lors de la prise du prolopa (pleins de mouvements) puis rapidement il est bloqué. Ce qu'il faut faire à ce moment-là, c'est réduire la dose et rapprocher les prises pour éviter ces suites de blocage-dyskinésie.

Quand le patient ne répond plus du tout au traitement, la seul alternative est de venir placer une électrode au niveau du noyau sous-thalamique (NST).

\section{Maladie de Huntington}

\section{Généralités :}

La maladie de Huntington est une maladie génétique qui se transmet sur le mode autosomique dominant. Cette maladie touche l'homme et la femme de manière équitable ( $1 \mathrm{~h}$ pour $1 \mathrm{f})$. Elle débute entre 30 et 50 ans. Le décès surviendra 15 ans après. La cause de la maladie est une expansion du triplet CAG sur le gène codant pour l'Huntingtine qui se trouve sur le chromosome 4 (attention maladie de Kennedy aussi expansion CAG aussi mais sur le chromosome X). Si l'expansion est supérieure à 40 , il y a chorée et si supérieure à 70 , début de la maladie à un stade précoce. Donc comme les maladies génétiques à expansion de triplet, il y aura des phénomènes d'anticipation et de potentiation. Des recherches génétiques ont été menées et on a découvert que d'autre locus pouvait accélérer ou ralentir la survenue de la maladie : on parle d'environnement génétique.

Notion d'environnement génétique qu'il a rajouté cette année :

- Il y a 3 régions qui accélèrent ou retardent le début des symptômes jusqu'à 6,1 ans ;

- 2 loci sur le chromosome 15 : 
1. 1 qui accélère le début des symptômes de 6,1 ans ;

2. 1 qui diminue le début des symptômes de 1,4 ans ;

- 1 locus sur le chromosome 8 qui accélère le début des symptômes de 1,6 ans ;

- Anomalie sur un gène du chromosome 3 intervenant dans la réparation de l'ADN.

Clinique :

Les signes que présentent les patients sont les suivants :

1. Chorée (dyskinésie) au stade précoce puis bradykinésie à un stade plus avancé;

2. Troubles psychiatriques et comportementaux ;

3. Démences (troubles cognitifs);

Mécanisme :

Dans la maladie de Huntington, il y a une perte diffuse des neurones et plus particulièrement une perte de neurones au niveau du noyau caudé (atrophie du noyau caudé). Pour rappel le noyau caudé fait partie du striatum.

Dans un stade précoce de la maladie, il y a une perte préférentielle des neurones dopaminergiques D2 au niveau du striatum (ou plus précisément du noyau caudé). Les récepteurs dopaminergiques D2 sont ceux de la voie indirecte qui inhibe le mouvement. La voie indirecte fonctionne moins bien et donc il y a moins d'inhibition, ce qui donne une dystonie et la chorée que l'on nomme chorée de Huntington.

Dans un stade plus tardif de la maladie, les neurones D1 de la voie directe vont aussi être touchés. Donc la voie directe qui facilite le mouvement fonctionne moins bien et le patient va donc présenter une bradykinésie et des rigidités. 
Comment peut-on expliquer cette perte neuronale?

Il y a une modification du système ubiquitine qui entraîne 2 choses :

1. Dysfonction du système ubiquitine-protéasome ;

2. Accumulation de chaines riches en polyubiquitines et en polyglutamines.

Ces 2 phénomènes ainsi qu'une inflammation importante (par génération de radicaux libres) expliquent en partie la perte de neurones au niveau du striatum.

Comment expliquez-vous les signes de la maladie de Huntington?

Dans la maladie de $\mathrm{H}$, il y a une perte diffuse des neurones et plus particulièrement une perte de neurones au niveau du noyau caudé (atrophie du noyau caudé). Pour rappel le noyau caudé fait partie du striatum.

Dans un stade précoce de la maladie, il y a une perte préférentielle des neurones dopaminergiques D2 au niveau du striatum (ou plus précisément du noyau caudé). Les récepteurs dopaminergiques D2 sont ceux de la voie indirecte qui inhibe le mouvement. La voie indirecte fonctionne moins bien et donc il y a moins d'inhibition, ce qui donne une dystonie et la chorée que l'on nomme chorée de Huntington.

Dans un stade plus tardif de la maladie, les neurones D1 de la voie directe vont aussi être touchés. Donc la voie directe qui facilite le mouvement fonctionne moins bien et le patient va donc présenter une bradykinésie et des rigidités. 


\section{Cervelet}

Cerebellum $($ en latin $)=$ petit cerveau

Le cervelet est divisé anatomiquement en 3 parties :

1. Le vermis (ou paleocerebellum);

2. Les lobes latéraux (ou néocérébellum) ;

3. Le lobe flocculo-nodulaire (ou archeocerebellum) ;

Le cervelet est divisé fonctionnellement en 3 parties :

1. Vestibulo-cerebellum (=lobe flocculo-nodulaire) pour l'équilibre et les mouvements oculaires ;

2. Spino-cerebellum (vermis + lobes intermédiaires) qui va influencer l'activité de la ME (moelle épinière) et TC (tronc cérébral) pour les muscles de la posture ;

3. Cérébro-cerebellum (une partie des hémisphères latéraux) pour les mouvements complexes (partie du cervelet la plus évoluée) ;

Le cervelet est composé de 3 noyaux de dedans vers le dehors :

1. Noyau fastigial ;

2. Noyau interpositus (globuleux emboliforme);

3. Noyau dentelé ;

Le rôle du cervelet est de trouver le meilleur ajustement possible du mouvement que l'on veut effectuer. Pour ce faire, le cerveau remplit 3 fonctions :

1. Une fonction motrice (précision et coordination du mouvement) ;

2. Une fonction sensitive (feed-back sensoriel pour lui permettre de comparer mouvement attendu et mouvement réalisé) ;

3. Une fonction cognitive (patrons de mouvement préprogrammés) ; 
Au niveau moteur, on peut aussi préciser que le cervelet jour un rôle important dans l'apprentissage moteur (quand on veut réaliser de nouveaux mouvements) et dans l'anticipation (principe des 5 caisses avec les 4 premières qui sont super lourdes et la 5ème qui est super légère).

La boucle motrice d'un mouvement lent est la suivante :

1. Couche 5 du cortex sensorimoteur (BA 4,6);

2. Qui projette sur les noyaux protubérantiels ;

3. Qui projettent sur le cervelet ;

4. Qui projette sur le thalamus (qui est une zone relais) ;

5. Qui projette à nouveau sur le cortex moteur.

Quel est le mécanisme de l'apprentissage au niveau du cervelet?

Le mécanisme d'apprentissage de nouvelles habilités motrices se fait de manière relativement inconsciente par apprentissage de ses erreurs (essais/erreurs/correction et ainsi de suite) La réalisation d'erreurs va entrainer des modifications synaptiques permettant l'apprentissage.

1. Concentration sur un nouveau mouvement

2. Premières réalisations : malhabiles, mal coordonnées

3. Entrainement : fluidité, automatisme

4. Acquisition de nouveaux programmes moteurs (de nouveaux patrons de mouvements)

Expliquez la théorie de l'apprentissage ainsi que ce qui stimule les différentes fibres et ce qui les inhibe pour annuler l'apprentissage? 
Différentes structures qui entrent en jeux :

1. Néocortex qui projette sur les noyaux du pont ;

2. Les noyaux du pont qui projettent des afférentes via les fibres moussues vers les cellules granulaires ;

3. Les cellules granulaires projettent des axones qui vont former les fibres parallèles de la couche moléculaire ;

4. Les fibres parallèles sont orientées perpendiculairement au plan des dendrites des cellules de Purkinje (PJ).

5. Les fibres parallèles forment des synapses avec l'arbre dendritique des cellules de PJ ;

6. Message venant de l'olive inférieure destiné à signaler une erreur dans le mouvement via les fibres grimpantes qui font des synapses excitatrices au niveau de PJ ;

7. Les axones de PJ forment des synapses inhibitrices au niveau des noyaux profonds du cervelet qui projettent vers le thalamus.

8. Stimulation des fibres parallèles produit des PPSE au niveau des cellules de PJ ;

9. Si stimulation simultanée de PJ par fibres grimpantes et fibres parallèles : perte d'amplitude du PPSE pouvant durer jusqu'à une heure. Il y a une dépression de l'efficacité de la synapse au niveau post-synaptique.

Quand on apprend à jouer à un sport, ce qu'on fait, c'est corriger ses erreurs. Quand on fait une erreur, l'activation d'une fibre grimpante (il y a une décharge qui arrive dans la fibre grimpante) va influencer la cellule de Purkinje (PJ). Cette cellule de PJ reçoit aussi les informations proprioceptives via les fibres parallèles des cellules granulaires. La fibre grimpante ainsi que les fibres parallèles font des synapses excitatrices au niveau de la cellule de PJ. Les fibres parallèles activent des canaux AMPA (il y a alors entrée de sodium) mais en même temps il y a activation d'un récepteur métabotropique au glutamate (induisant la stimulation d'une protéine $G$ puis la production de DAG qui activera une PKC). Si l'activation de la cellule de PJ par une fibre parallèle se fait simultanément à 
l'activation de cette même cellule de PJ par une fibre grimpante, cela va entraîner une modification de la sensibilité du récepteur AMPA à l'activité des fibres parallèles. Cette modification de la sensibilité va persister de manière prolongée. C'est ça le mécanisme d'apprentissage. On rend le récepteur AMPA moins sensible au glutamate. Il y a une perte d'amplitude des PPSE.

Donc à chaque fois qu'on fait une erreur, l'influx de la fibre grimpante arrive en même temps que les informations proprioceptives des fibres parallèles. C'est de cette façon qu'on apprend et qu'on va retenir des patrons de mouvements qui permettent une activité motrice correcte.

Lors de la génération d'un nouveau patron, il existe un centre excitable (LTP =potentiation à long terme) et autour une zone d'inhibition (LTD= long term depression). Ces zones d'inhibition sont permises grâce à des interneurones inhibiteurs comme les cellules de Golgi, les cellules étoilées et les cellules en panier.

Il est essentiel d'avoir une activation des canaux calcium pour avoir ce phénomène d'apprentissage. Donc si on bloque l'entrée de calcium, on peut inhiber l'apprentissage. On se souvient que dans la maladie de Lambert-Eaton, il y a blocage de canaux calcium au niveau présynaptique. Donc chez certains LE, en + d'avoir une pathologie de la jonction neuromusculaire, ils développent des tableaux de type cérébelleux. Attention aussi aux chélateurs de calcium qui peuvent bloquer les canaux calcium des cellules de PJ.

Qu'est-ce que le LTD ? Que se passe-t-il lors des mouvements balistiques?

Quand on apprend un nouveau mouvement (marcher, tennis, vélos), on va générer un nouveau patron. Ce patron est caractérisé par un centre excitable (LTP= potentiation à long terme) entouré 
d'une zone d'inhibition (LTD= dépression à long terme). Cette zone d'inhibition est générée par des 3 types d'interneurones inhibiteurs à savoir :

1. Cellule en panier ;

2. Cellule étoilée ;

3. Cellule de Golgi ;

Durant les mouvements balistiques (ex : baseball où on réalise un mouvement rapide pour frapper la balle le plus fort possible pour que la balle aille le plus vite possible et ainsi éviter que l'adversaire n'arrive à toucher la balle avec sa batte) : on n'a pas le temps de réaliser un feedback. Les fibres grimpantes (rôle d'apprentissage) ne peuvent donc pas modifier le mouvement en fonction des informations sensorielles. Elles vont par contre détecter une erreur dans le mouvement et modifier le programme pour le mouvement suivant.

Qu'allons-nous avoir lors de l'exérèse de cervelet?

Le cervelet n'influence en rien l'intensité de la force que l'on met quand on doit réaliser un mouvement. De même il ne modifie pas non plus les circuits sensitifs. Ce sont les circuits sensitifs qui influencent le cervelet et non l'inverse.

Donc lorsqu'il y a exérèse du cervelet il y a :

1. Aucune modification de l'intensité de la contraction ;

2. Aucune modification de la sensibilité ;

3. Modification de la précision spatiale et de la coordination temporelle du mouvement ;

4. Modification de l'équilibre et diminution du tonus (tonus= résistance d'un muscle lorsqu'il est étiré de manière passive) : hypotonie !;

5. Modification des capacités d'apprentissage moteur ; 
6. Altérations de certaines fonctions cognitives nécessaires pour la réalisation de mouvements complexes

A quoi sert le vestibulo-cerebellum ? Qu'est-ce que le reflexe vestibulo-oculaire? Quels seront les troubles suite à une lésion du vestibulo-cerebellum ?

- Le vestibulo-cerebellum permet l'équilibre et les mouvements oculaires.

- Le réflexe vestibulo-oculaire permet de maintenir les yeux sur une cible lorsque la tête tourne. L'activation des NC 3 et 6 n'est pas suffisante pour avoir un bon réflexe vestibulo-oculaire. Le système vestibulaire (canaux semi-circulaires et otoconies) va projeter sur le vestibulo-cerebellum (lobe flocculo nodulaire) et cette partie du cervelet va permettre à ce que la cible soit bien fixée sur la rétine.

- Suite à une lésion du vestibulo-cerebellum, on remarquera

1. Des troubles de l'équilibre qui se caractérisent par:

- un élargissement de la base de sustentation ;

- une marche irrégulière avec jambes et bras écartés (=marche ébrieuse) ;

- des oscillations à la station debout ;

- tendance à la chute (yeux fermés ou ouverts) ;

- signe de la danse des tensions (déformations des tendons qui vont dans tous les sens pour pouvoir rester debout);

2. Nystagmus pathologique (les yeux bouges en absence de rotation de la tête à opposer au nystagmus vestibulaire qui est physiologique et qui correspond au repositionnement des yeux lors d'une rotation soutenue de la tête).

3. Incapacité à inhiber le réflexe vestibulo-oculaire ; 
Pourquoi une lésion au cervelet donne des vertiges et définir vertiges?

- Dans le cervelet, on peut décrire plusieurs zones dont le vestibulo-cerebellum qui permet l'équilibre et les mouvements oculaires.

Par conséquent, si le cervelet est lésé, l'équilibre n’est plus assuré $\rightarrow$ vertiges.

- Vertiges = troubles de l'équilibre $:$ - Elargissement de la base de sustentation

- Vomissement

- Chutes (yeux ouverts ou fermés)

Quels sont les signes suite à une lésion du vermis (et du noyau fastigial) ? de même si lésion au niveau du noyau interpositus

- Suite à une lésion du vermis : (chat décervelé)

1. Atteinte axiale et du tronc (prise d'une position antigravitaire) : ne parvient pas à rester assis dans son lit ;

2. Élargissement de la base de sustentation pour éviter de tomber;

3. Dysarthrie (voie scandée et difficulté du contrôle facial et vocal)

Peut être due à un alcoolisme chronique ou un syndrome de Wernicke (déficit en B1=thiamine)

- Suite à une lésion du noyau interpositus : (singe avec son levier où on refroidit noyau dentelé et interpositus)) :

1. Tremblement d'action (quand on se rapproche de la cible, le tremblement augmente) ;

2. Délai d'initiation des mouvements (retard dans le début des mouvements) ;

3. Mouvements décomposés (pas fluide); 
4. Altération des mouvements de pince (pouce-index) qui est un mouvement qui demande une coordination précise.

Quels sont les signes d'une atteinte de noyau dentelé dans le cervelet latéral (Cérébro-cerebellum: partie du cervelet la plus sophistiquée) ?

Le noyau dentelé permet l'acquisition et le traitement d'informations sensitives pour des tâches nécessitant une évaluation spatiale et temporelle complexe, importantes pour programmer des actions motrices complexes et des séquences de mouvement.

Signes d'atteinte du noyau dentelé :

1. Hypotonie (attention dans syndrome pyramidal et parkinson, c'est une hypertonie);

2. Réflexes pendulaires;

3. Ataxie (manque de coordination dans le mouvement) :

- Délai pour initier mouvement ;

- Erreur d'amplitude des mouvements (dysmétrie);

- Erreur de fréquence et de régularité des mouvements (dysdiadochokinésie) ;

- Décomposition des mouvements ;

- Asynergie (agoniste-antagoniste : cf. expérience du singe avec levier) ;

4. Tremblement d'action 
Expliquez le tremblement essentiel

Dans la maladie de Parkinson, c'est un tremblement de repos. Ici le tremblement essentiel est un tremblement d'action. Tous les tremblements sont exacerbés avec le stress. Il suffit de faire faire un calcul à un patient pour qu'il stresse et qu'on voit son tremblement qui augmente. Donc le tremblement parkinsonien est un tremblement de repos alors que le tremblement essentiel est un tremblement d'action et de maintien d'attitude. Le cervelet semble un élément essentiel dans la survenue de ces tremblements essentiels.

- Épidémiologie :

- Après 50 ans : $4 \%$ de la population

- L'âge augmente l'amplitude des tremblements mais diminue la fréquence

- Facteurs familiaux (60\% de concordance chez des jumeaux monozygotes)

- Caucasiens > Afro-américains

- Facteurs environnementaux

- Facteurs associés : éléments de la famille des alcaloïdes et plus particulièrement des $\beta$-carbolines. Ceux-ci proviennent des barbecues ou d'une production endogène. Leur taux est supérieur dans les tremblements essentiels.

- Facteurs modifiant : - Café : augmente

- Alcool : diminue

- Clinique :

- Touche : membre supérieur $>$ tête $>$ tronc

- Fréquence de 4 à $12 \mathrm{~Hz}$ 
- Provoque de l'instabilité posturale et de l'ataxie (mais pas de nystagmus et pas de voix scandée)

- Maladie dégénérative où on observe :

- Augmentation de l'activité de la voie olivocérébelleuse

- Changements de la voie cérébello-thalamo-corticale

Traitement :

1. Alcool ;

2. Propanolol (bétabloquant) ;

3. Primidone (barbiturique)

4. Mais effets secondaires ++ donc si tremblement trop important chirurgie où on provoque lésion du noyau thalamique ventrointermédiaire $(=\mathrm{VIM})$ avec obtention d'une réduction de $90 \%$ des tremblements. 